\title{
Arqueología regional en Tierradentro, Cauca, Colombia
}

\author{
Carl Henrik Langebaek \\ Doctor en Antropología, Universidad de Pittsburgh \\ Decano Facultad de Ciencias Sociales, Universidad de los Andes \\ clangeba@uniandes.edu.co \\ Alejandro DeVer \\ Doctor en Antropología, Universidad de Pittsburgh \\ alejandro.dever@gmail.com
}

\begin{abstract}
Resumen
NVESTigACIONES REALIZADAS EN LA REGIÓN DE TIERRADENTRO, DEPARTAMENTO DEL CAUCA, DURANTE más de cinco años, aportan información sobre la secuencia de cambio social desde la primera ocupación por parte de grupos alfareros hasta después de la Conquista española. El artículo presenta información importante con respecto a la dinámica de asentamientos, cambios demográficos y relaciones entre la ocupación humana y el paisaje a lo largo de más de 2.000 años de historia. Se sugiere que el desarrollo de las famosas manifestaciones de jerarquía social (montículos, estatuaria) no es el resultado de presiones de población o del control de las tierras más fértiles a nivel regional. Por otra parte, se hacen comparaciones sobre los procesos ocurridos en Tierradentro con la vecina región del Alto Magdalena.

PALABRAS ClaVE: cacicazgos, arqueología, Colombia, indígenas, Tierradentro, Colombia
\end{abstract}

\section{Regional Archaeology In Tierradentro, Cauca, Colombia}

\begin{abstract}
DESEARCH CARRIED OUT FOR MORE THAN 5 YEARS INTO SETTLEMENT PATTERNS IN THE TIERRADENTRO Rregion, Cauca Department, has provided information of the sequence of social change from early ceramists up to after the Spanish Conquest. This paper makes available information regarding settlement patterns, demographic change and relations between human occupation and landscape for a period that encompasses more than 2.000 years of history. It is claimed that the well known manifestations of social hierarchy (mound, statuary) is not the result of population pressure or the need to control the most fertile lands at the regional level. Comparisons between Tierradentro and the neighboring zone of San Agustin are provided.

KEY WORDs: Chiefdoms, archaeology, Colombia, native Americans, Tierradentro,
\end{abstract} Cauca

\section{Revista Colombiana de Antropología}

Volumen 45 (2), julio-diciembre 2009, pp. 323-367 
Arqueología regional en Tierradentro, Cauca, Colombia

\section{INTRODUCCIÓN}

A REGIÓN ARQUEOLÓGICA DE TIERRADENTRO ESTÁ LOCALIZADA EN LA
Cordillera Central de Colombia, en el departamento del Cauca,
y colinda por el sur con la célebre zona arqueológica de San Agustín. Se trata de un territorio montañoso, de alta diversidad climática y ecológica, cortada por profundos cañones formados por ríos que descienden de los páramos y desembocan en el río Páez el que, a su vez, lleva al río Plata y en últimas al Magdalena. La altura en metros sobre el nivel del mar, msmn, oscila entre los 800 y los más de 5.500 del Nevado del Huila. Sólo en la Quebrada de San Andrés se encuentran alturas que varían entre los I.200 y los 2.600 msnm (Guhl, A., I996, p. 68). En términos de pluviosidad la precipitación media anual asciende a los I.350 $\mathrm{mm}$ en la parte más baja, y llega hasta los $2.000 \mathrm{~mm}$ en los 2.500 msnm (Sevilla Casas, E., I976, p. IO). Tierradentro es conocida por la presencia de estatuas similares a las de San Agustín e hipogeos que han servido para hablar de la "cultura Tierradentro", objeto de numerosas investigaciones interesadas en conocer mejor las características de sus monumentos y sus relaciones con San Agustín (Pérez de Barradas, J., I937a; Hernández de Alba, G., I938; Silva, I943; Yanguez, J., I968; Long, S. y Yanguez, J., I97I; Groot, A. M., 1974; Chaves, A. y Puerta, M., 1985, 1986, 1990a).

Desde 1994, y por más de cinco años, el Proyecto Arqueológico Tierradentro, $\mathrm{PAT}^{1}$, con el apoyo del Instituto Colombiano de Antropología e Historia, ICANH, y la Universidad de los Andes, comenzó a estudiar la región tomando como referencia el Proyecto del Valle de la Plata que desde hace años ha aportado invaluable información sobre los procesos de cambio social ocurridos en San Agustín (Drennan, R., I984, 2000). El PAT comparte con los proyectos realizados en esta última región el objetivo de

I. La presente investigación fue posible gracias al apoyo del Instituto Colombiano de Antropología e Historia, ICANH, que bajo la dirección de Myriam Jimeno y María Victoria Uribe, apoyó la propuesta. Asimismo, reconoce la contribución de la Universidad de los Andes y de la Universidad de Pittsburgh. Los autores agradecen los comentarios constructivos de los dos evaluadores anónimos que leyeron la primera versión del texto. Asimismo a Luis Gonzalo Jaramillo por sus oportunos comentarios. estudiar el desarrollo social y político de las sociedades humanas prehispánicas y además participa de la metodología común de reconocimiento regional lo cual permite hacer comparaciones (Langebaek, C. H., I995a y b). Como las de San Agustín, las sociedades que encontraron los 
españoles en Tierradentro fueron clasificadas como "cacicazgos”, categoría que aún tiene cierta utilidad aunque se reconoce que se trata de sociedades muy diversas tanto en términos de la base de poder (Feinman, G., y Neitzel, J., 1984), el carácter individual o colectivo del liderazgo (Earle, T., I996), y el papel de condiciones tecnológicas, ambientales y demográficas en las que se desenvuelven (Drennan, R., I996 y Langebaek, C. H., 2004). Los estudios arqueológicos llevados a cabo en diversas partes de Colombia han contribuido a establecer que los "cacicazgos" difirieron notablemente en muchos de los anteriores aspectos (Drennan, R., I996, 2008). Sin embargo, pese al enorme valor de investigaciones previas (Long, S. y Yanguez, J., I971; Groot, A. M., I974; Chaves, A. y Puerta, M., I985; 1986), es poco lo que Tierradentro ha contribuido en los debates contemporáneos sobre las sociedades indígenas prehispánicas. Si bien no parece muy riesgoso llamar "cacicazgos" a las sociedades que encontraron los españoles en Tierradentro, no es clara la naturaleza de su trayectoria ni es posible establecer comparaciones con otras regiones más allá de las características formales de su estatuaria o de su alfarería. Se espera que con esta publicación se dé un primer paso para corregir esa situación.

Hasta el momento, el PAT ha investigado $2 \mathrm{II} \mathrm{km}^{2}$, distribuídos en cuatro cuencas (San Andrés, $36.6 \mathrm{~km}^{2}$; río Negro, 92.5 km²; Malvasá, $53.6 \mathrm{Km}^{2}$ y Ullucos, 29.I km²), la mayor parte de las cuales corresponde a empinadas estribaciones de la cordillera, excepto por algunas zonas planas, entre ellas el Plano de Segovia y El Hato (mapa I, foto I y 2). Este informe presenta los resultados del PAT con respecto a una serie limitada de temas: la reconstrucción cronológica, la identificación del comportamiento demográfico, la relación entre la ocupación humana y el paisaje a nivel regional, el desarrollo de centros ceremoniales y las relaciones entre los diferentes períodos de ocupación prehispánica, en especial entre el último y el poblamiento de los nasa (antes paeces) actuales. El Proyecto incluyó otros aspectos que no se tratan en esta publicación: la distribución de la estatuaria, los actuales asentamientos nasa, la producción de cerámica contemporánea, el impacto de las características de visibilidad en la distribución de asentamientos y la excavación de viviendas. 

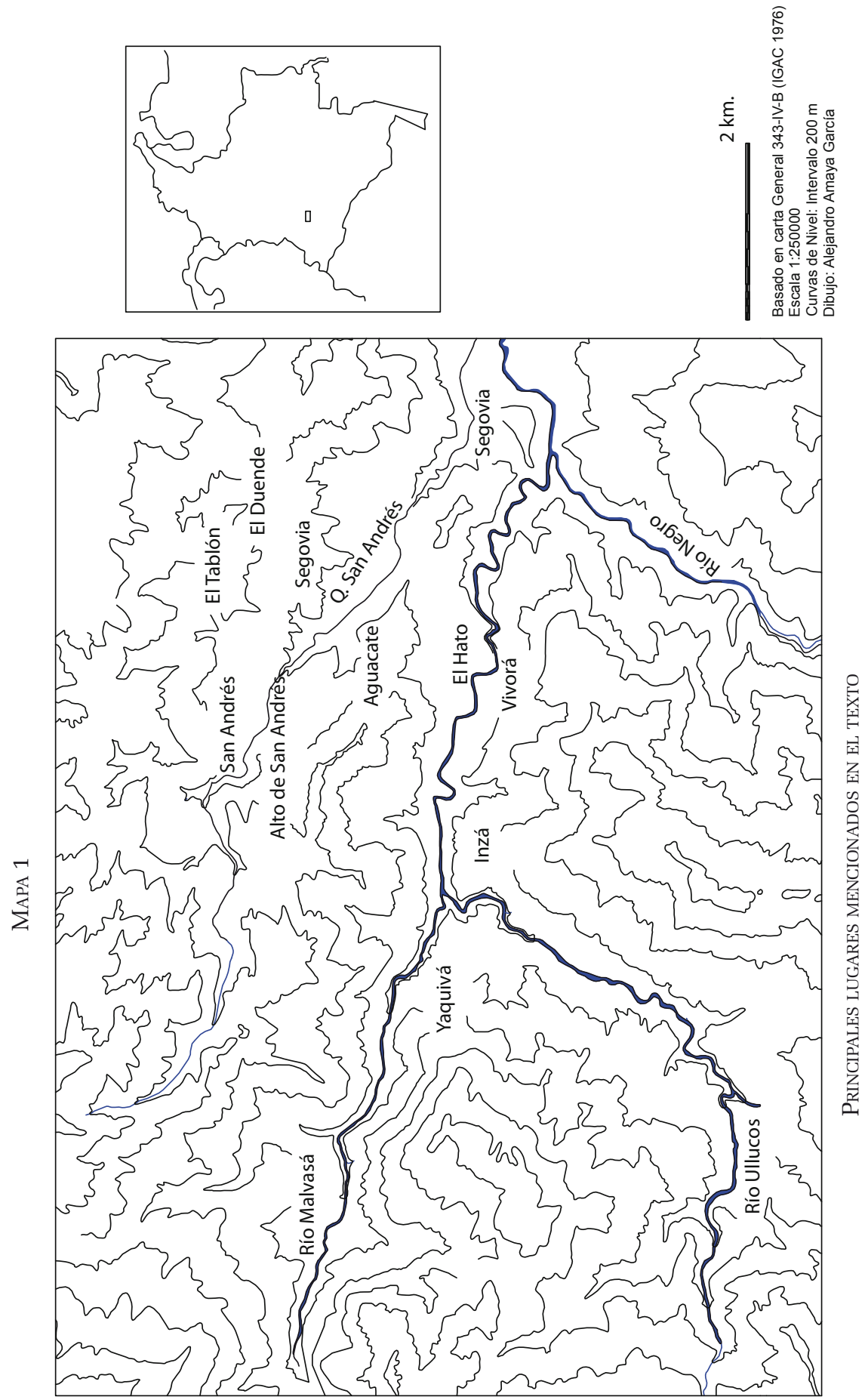
Revista Colombiana de Antropología

Foto 1

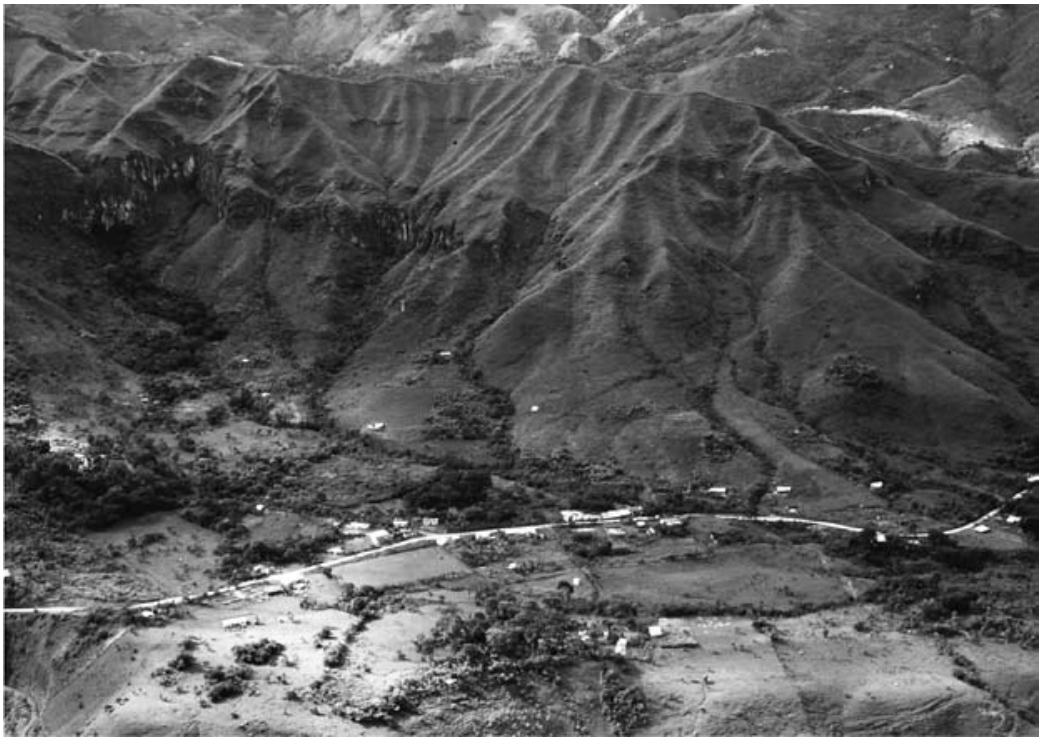

Paisaje de Tierradentro. El Hato en el primer plano; al fondo la cuenca de la Quebrada de San Andrés

Foto 2

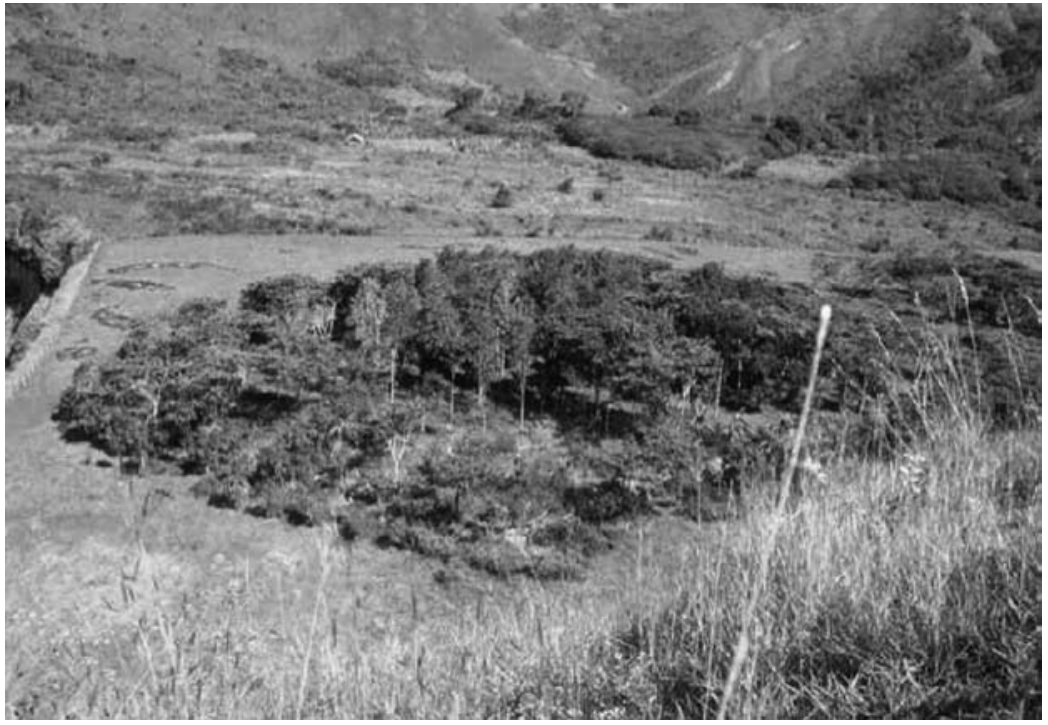

Paisaje del Plano de Segovia 
Arqueología regional en Tierradentro, Cauca, Colombia

\section{Cronología}

U

N ESFUERZO CONSIDERABLE DEL PAT SE ORIENTÓ A ESTABLECER UNA cronología confiable. A grandes rasgos, se diferenciaron cinco períodos: Temprano I, 2 y 3, Medio y Tardío, que son equivalentes a los períodos Formativo I, 2 y 3, Clásico Regional y Reciente del Proyecto Valle de la Plata (Drennan, R., et al. 2006), aunque con modificaciones en cuanto a su duración. Los tipos cerámicos más característicos del Alto Magdalena están presentes en Tierradentro, pero aparecen variaciones importantes e incluso algunos tipos locales, en especial en los períodos Tempranos y Tardío. Además, se tuvo en cuenta el período posterior a la Conquista española llamado Moderno. El establecimiento de la cronología se basó en excavaciones realizadas en el Plano de Segovia, lugar donde se encontraron más de Ioo mil fragmentos de cerámica en su mayoría asociados a la producción de sal y se obtuvieron cinco dataciones radiocarbónicas que abarcan desde la ocupación temprana hasta el Período Medio (Blick, J., I996). También, en tres cortes realizados en El Hato, donde se encuentran evidencias de montículos y estatuaria (Zarur, F., I998), un depósito asociado a una vivienda reciente ubicada en el costado norte del río Ullucos y terrazas de vivienda excavadas en Inzá (Cuéllar, A., I997; Giraldo, S., I997; Humar, Z., I998 y Rubiano, J. C., I999).

Con base en las dataciones obtenidas se propuso la cronología resumida en la Tabla I. Como se anotó más arriba, se trata de una propuesta muy similar a la del Proyecto Valle de La Plata, aunque con algunas modificaciones en la duración y nombre de los períodos. En primer lugar, las excavaciones en El Hato apoyan la propuesta de L. G. Jaramillo (I996, p. 75) en cuanto a que la cerámica Planaditas que sirve para identificar el Período Temprano 2 coexistió durante un buen tiempo con la alfarería Lourdes, que define el Período Temprano 3. Se encontraron razones para modificar levemente la cronología de los períodos Temprano 3, Medio y Tardío. El primero se prolonga algo más en Tierradentro, mientras el segundo además de iniciar algo más tarde culmina bastante después, lo que implica que el Período Tardío inicie más tarde también (Tabla I). Además, el proyecto incorporó un período posterior a la Conquista identificado por cerámica que continúa siendo elaborada hasta nuestros días en Pedregal, río Negro y Vivorá y que aparece en el reconocimiento regional (Giraldo, S., I995). 
TABLA I. Tipos CERÁMICOS Y CRONOLOGÍA EN TIERRADENTRO

\begin{tabular}{|l|l|l|l|l|}
\hline Cerámica & \multicolumn{1}{|c|}{$\begin{array}{c}\text { Cronología en } \\
\text { Tierradentro }\end{array}$} & $\begin{array}{c}\text { Nombre del } \\
\text { período }\end{array}$ & $\begin{array}{c}\text { Cronología } \\
\text { en el Alto } \\
\text { Magdalena }\end{array}$ & $\begin{array}{c}\text { Nombre del } \\
\text { período en Alto } \\
\text { Magdalena }\end{array}$ \\
\hline Rionegro & 1650 d. C.-presente & Moderno & - & - \\
\hline Tardía & $1300-1650$ d. C. & Tardío & $900-1530$ d. C. & Reciente \\
\hline Guacas & $100-1300$ d. C. & Medio & 1-900 d. C. & Clásico Regional \\
\hline Lourdes & 300 a. C.-100 d. C. & Temprano 3 & 300 a. C.- 1 d. C. & Formativo 3 \\
\hline Planaditas & $600-300$ a. C. & Temprano 2 & $600-300$ a. C. & Formativo 2 \\
\hline Tachuelo & $1000-600$ a. C. & Temprano 1 & 1000-600 a. C. & Formativo 1 \\
\hline
\end{tabular}

Fuente: Información sobre el Alto Magdalena tomada de R. Drennan (I993).

Un aspecto que aún no tiene respuesta definitiva es la cronología de los hipogeos de Tierradentro. Entre los objetivos del PAT no se ha incluido aún la excavación de estas estructuras, aunque un mejor conocimiento de su cronología ayudaría a conocer más la naturaleza de las sociedades que ocuparon la región y sus procesos de cambio. Su distribución no es igual a la de la estatuaria; de hecho, no se han encontrado hipogeos por fuera de la cuenca de la Quebrada de San Andrés, mientras que la distribución de la estatuaria es más amplia (mapa 2). Sin embargo, no se debe saltar a conclusiones precipitadas puesto que en San Agustín se han hallado estructuras similares, aunque mucho más pequeñas, así como cerámica comparable a la que se halla en los hipogeos de Tierradentro (Langebaek, C. H., I998). Muchas veces estos se encuentran en filos de difícil acceso que no fueron sitios de ocupación, como el caso de El Aguacate. No obstante, otras áreas con hipogeos sí están asociadas con áreas que tienen alguna evidencia de vivienda, como es el caso de Segovia. En las excavaciones de M. Puerta (1973, p. 166) realizadas en ese lugar, se halló cerámica como parte del relleno que parece corresponder al Período Medio, pero la asociación entre esa alfarería y los hipogeos no es clara. Dos fechas obtenidas por A. Chaves y M. Puerta son muy diferentes entre sí y no es fácil que las dos puedan ser válidas al mismo tiempo: una es de 770 +/- 240 a. C. y otra de 850 +/- 220 d. C. (Chaves, A. y Puerta, M., I99ob, p. 36). Por las características de la cerámica encontrada dentro de los hipogeos, el PAT se inclina a considerar que estos 
corresponden a la parte más tardía del Período Medio o incluso al Período Tardío, es decir, que son contemporáneos a un entierro similar encontrado en el sitio de Rancho Grande, en la región de Cumbre-Pavas, por el Proyecto Calima asociado a una fecha de I060 +/- 70 d. C. (Gähwiler-Walder, T., I988, p. 54). Por cierto, dos fechas adicionales obtenidas por el PAT de muestras de restos humanos en hipogeos de el Alto de Segovia, resultaron contaminadas por material proveniente de la toba volcánica (4470 +/- I30 a. C. A 29085 y 2770 +/- IIO a. C., A 29086).

MAPA 2

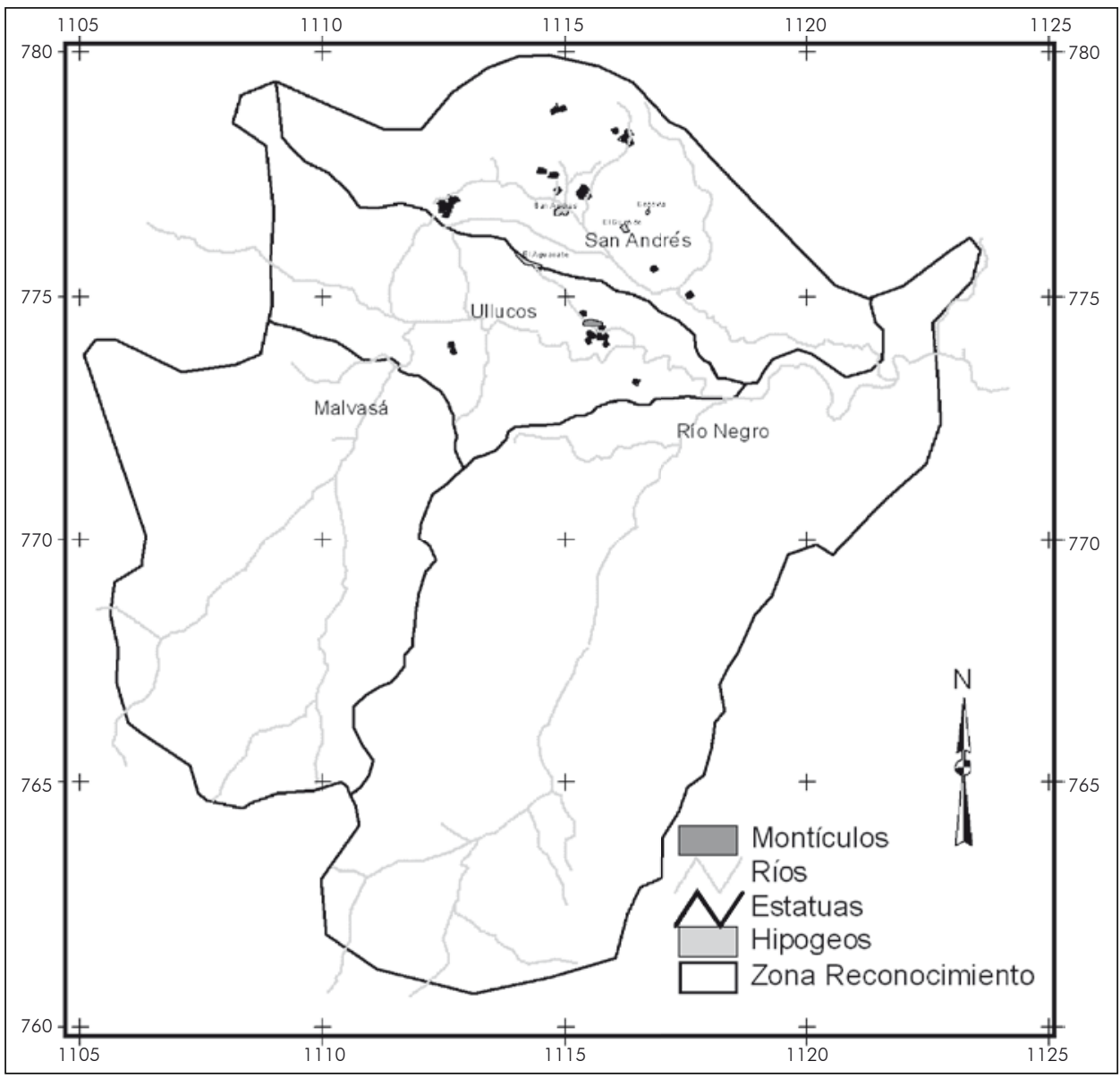

DisTRIBUCIÓN DE HIPOGEOS Y ESTATUARIA EN EL ÁREA DE ESTUDIO 


\section{Períodos ARQueológicos}

\section{Período Temprano I}

CE DEFINE A PARTIR DEL TIPo TACHUELO. Si BIEN NO CUENTA CON DATACIONES radiocarbónicas en Tierradentro, su posición estratigráfica es la más antigua, tanto en El Hato como en el Plano de Segovia, lo que confirma los resultados obtenidos en el Valle de la Plata donde Tachuelo corresponde a la alfarería más antigua. Durante el reconocimiento no se encontraron evidencias de ocupaciones más tempranas, lo que no quiere decir que no existieran sino que debieron ser muy pequeñas. Es necesario tener en cuenta que en el Alto Magdalena se ha propuesto la introducción de la agricultura antes que la cerámica (Llanos, H., I993, p. 53) y que ocupaciones de esa naturaleza escapan con facilidad a la metodología utilizada en este proyecto. En total se identificaron I8 pruebas con cerámica de este período, para un total de ig hectáreas habitadas, es decir tan solo un $0.09 \%$ del área estudiada. A diferencia de lo que sucede en el Valle de la Plata es difícil reconocer concentraciones de población (mapa 3).

Una de las características mas importantes de este período es que no se encuentran evidencias de ocupación humana en los suelos más pobres, difíciles de explotar con tecnología simple; de hecho, la población prefirió concentrarse en suelos de buena calidad, sobre todo en el Plano de Segovia y en El Hato, dos de los lugares planos y relativamente fértiles del área de estudio, aunque muchos de los mejores suelos no tienen evidencia alguna de ocupación. Desde cualquier perspectiva, se trata de una baja densidad de población, característica que es similar con respecto al mismo período en el Valle de la Plata (Drennan, R., et al., I99I, p. 307). No conocemos mayor cosa sobre las viviendas Tempranas, ni sobre las prácticas funerarias. A. Chaves y M. Puerta (1985, p. 70) ilustran una alcarraza que parece corresponder al tipo Tachuelo, cuyo contexto es desconocido hasta el momento. Otro hallazgo muy interesante, pero lejano de la región objeto del presente informe, es el que reportan C. Gnecco y J. R. Martínez (1992), correspondiente a una tumba de pozo con cámara lateral en la vereda Tarabita, cerca de Mosoco y que contenía cerámica Ilama de la región Calima, producida, sin embargo, durante un período de cerca de I.00o años (IOOO a. C.-O), por lo que es complicado 
saber a cuál de las subdivisiones del Período Temprano se asocia el material.

\section{MAPA 3}

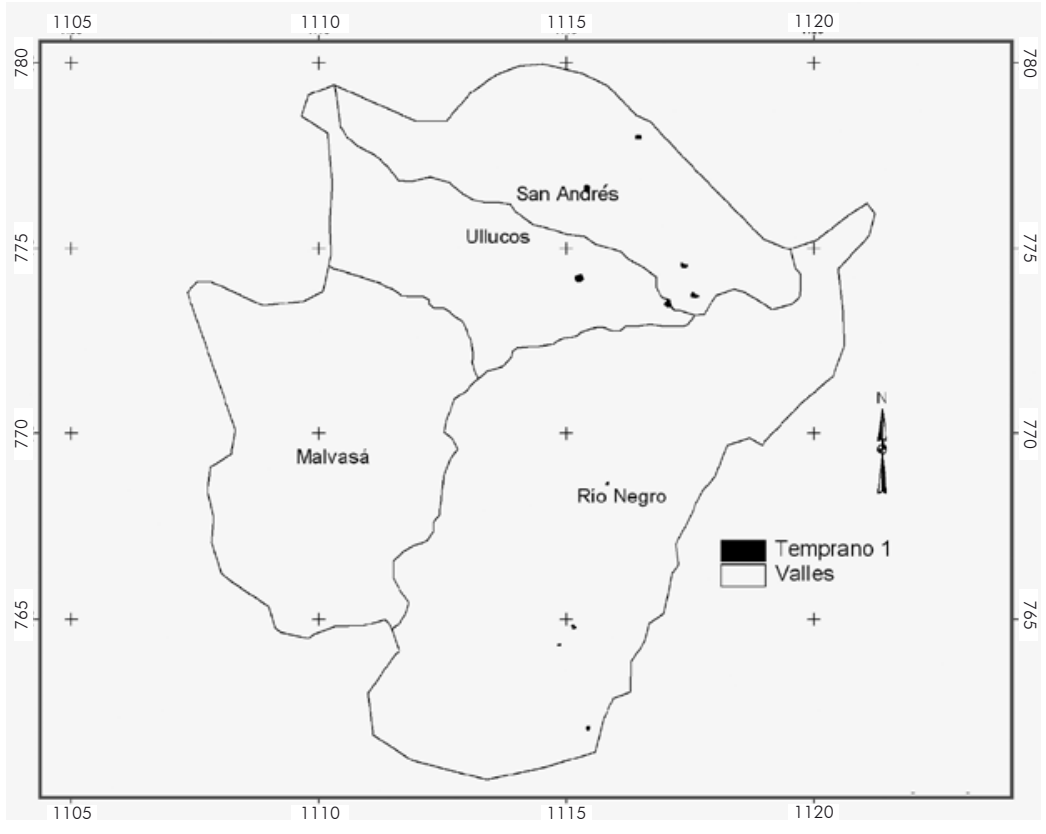

Distribución de asentamientos durante el Período Temprano i.

\section{Período Temprano 2}

Como en el Valle de la Plata, se define a PARTir de la CERÁmica Planaditas. No se tienen fechamientos radiocarbónicos para Tierradentro, pero la posición de ese material en las excavaciones realizadas en El Hato y en Segovia ratifica una posición cronológica comparable. Para este período se identificaron 32 pruebas distribuidas en 31.35 hectáreas de ocupación, lo que representa un considerable aumento con relación al Temprano I. Sin embargo, aún se trata de una baja densidad, que apenas equivale al o.I5\% del área reconocida (mapa 4). La asociación de la ocupación Temprano 2 con los mejores suelos es bastante buena, si bien algunas tierras de malas condiciones para la agricultura fueron ocupadas y suelos de muy buenas condiciones no fueron habitados. Por lo demás, al igual que durante el período anterior, no se identifican núcleos de población, aunque se pueden reconocer algunas agregaciones algo más concentradas en el Plano de 
Segovia y en El Hato, así como en la cuenca de los ríos Ullucos y Negro. Los cambios en relación con el Período Temprano 3 son pocos: el área ocupada en la cuenca del río Negro disminuye mientras que el poblamiento de la parte alta de la cuenca de San Andrés aumenta.

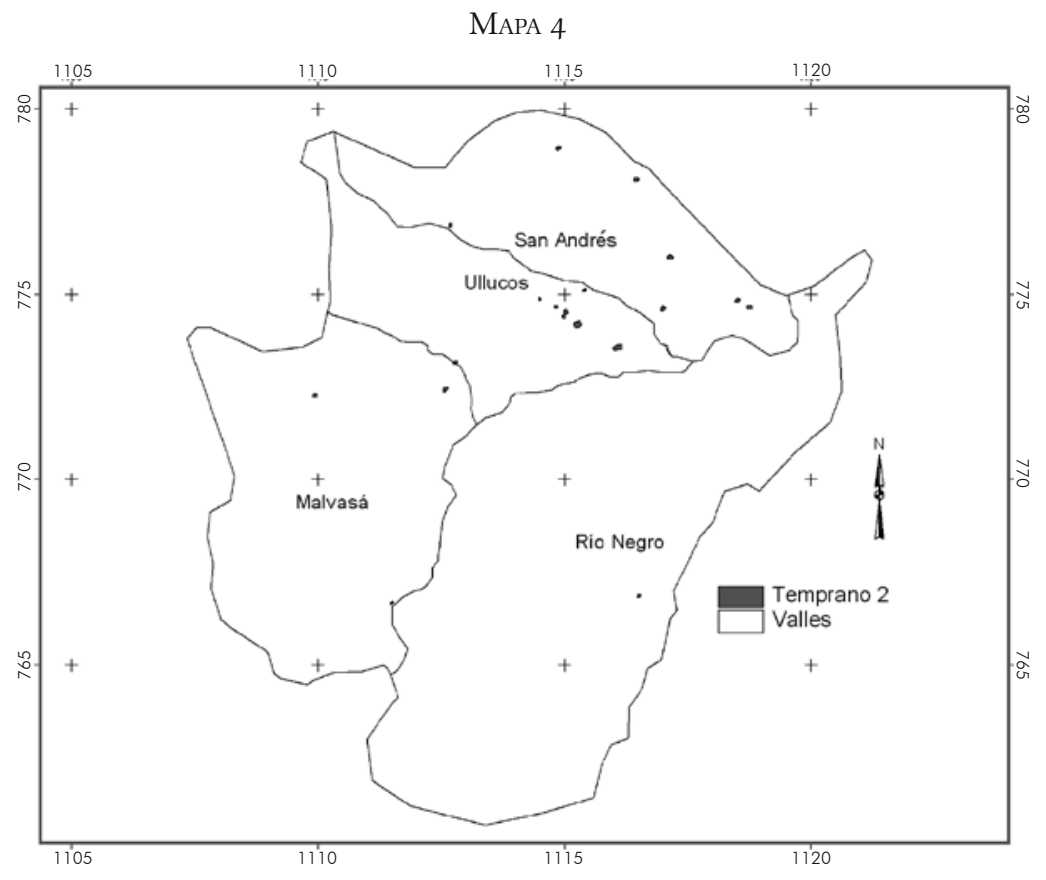

Distribución de asentamientos DURAnte el Período Temprano 2.

\section{Período Temprano 3}

CE ASOCIA CON LA CERÁMICA LOURDES, ENCONTRADA EN I92 PRUEBAS QUE cubren un total de I80.7 hectáreas. En el Hato (Corte II) se reportan tres fechas asociadas a niveles donde la cerámica $L o-$ urdes es predominante: $58+/-45$ d. C. (A 29083), I25 +/-45 d. C. (A 29082) y $160+/-50$ d. C. (A 29084), que sugieren que el Temprano 3 empieza algo más tarde que en el Alto Magdalena. Este período coincide con algunos de los cambios más importantes a lo largo de la secuencia arqueológica en Tierradentro, lo que también es cierto en el caso del Alto Magdalena. En primer lugar, el aumento en la ocupación es considerable: las hectáreas con evidencias de habitación equivalen al 0.85\% del área reconocida, en contraste 
con el 0.15\% del período anterior. Ahora la mayor parte de la región está ocupada, aunque no se distribuye de forma homogénea (mapa 5). En el caso del Alto Magdalena cambios similares se han asociado a un cambio del clima que mejoró las condiciones agrícolas (Drennan, R. y Quattrin, D. W., I996, p. 88), lo que también podría ser válido en Tierradentro. En la quebrada de San Andrés el aumento es considerable, mientras en la cuenca del río Negro el incremento es menor. En segundo lugar, se empiezan a reconocer cambios importantes en el patrón de poblamiento, en especial el desarrollo de una concentración de población en el Plano de Segovia y de otras menores en los alrededores de San Andrés.

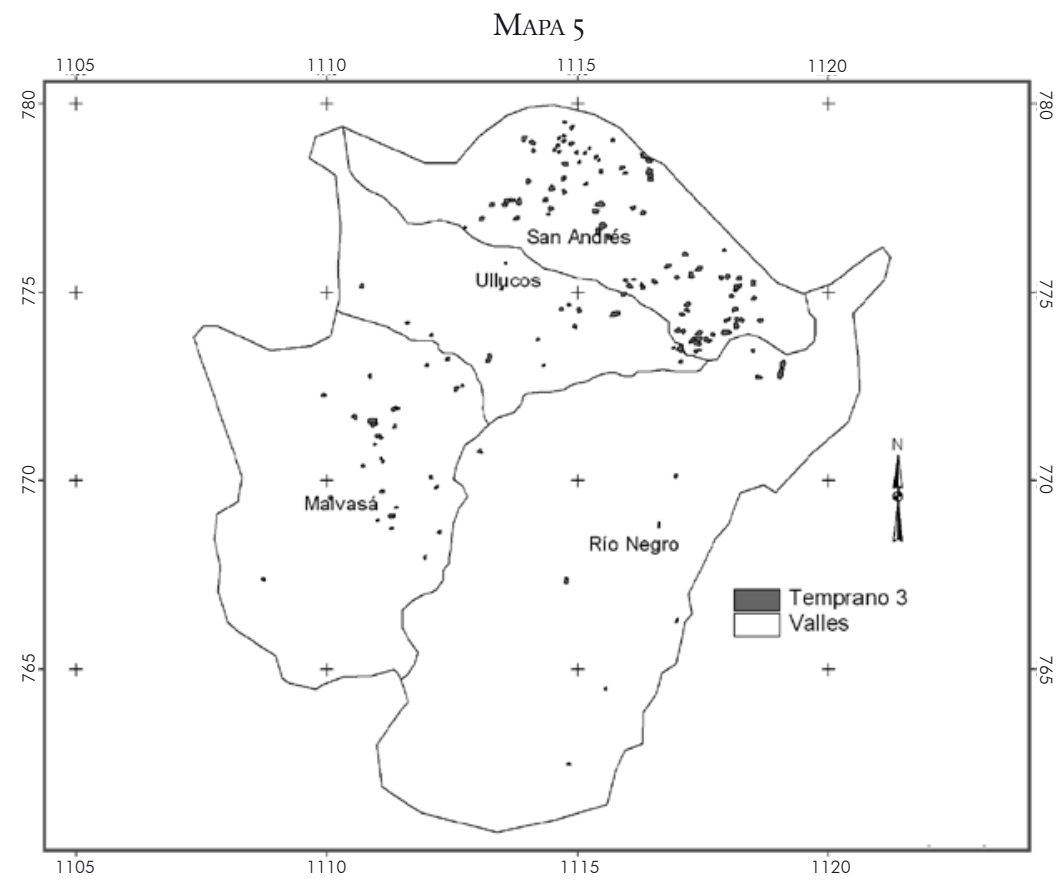

Distribución de asentamientos durante el Período Temprano 3

Existen algunos indicios de que importantes transformaciones sociales asociadas al Período Medio pudieron comenzar aquí. Cuando se estudian en detalle algunas de las concentraciones del Período Medio, que es el relacionado con la estatuaria, se hallan claros antecedentes en esta ocupación. Un ejemplo de ello es el sitio de El Hato, donde se encuentra una concentración del Período Medio, así como estatuas, montículos y petroglifos y donde las excavaciones reportan una importante ocupación Temprano 3 
(Zarur, F., 1998). En el caso de El Hato es importante resaltar que la ocupación Temprano 3 se vincula a una gran proporción de copas y cuencos que sugieren actividades de distribución de alimentos y bebidas. Merece destacarse de las excavaciones en El Hato el hallazgo de cerámica muy fina, con una significativa cantidad de fragmentos de cerámica decorados, así como de una concentración de cerámica con el mismo comportamiento cronológico de la alfarería Lourdes, pero que tiene características tipológicas distintas; además en este sitio aparecen fragmentos de cerámica asociados a la explotación de sal, cuya tipología se reconoce en el sitio excavado por A. M. Groot y luego, en el marco del presente proyecto, por J. Blick (Zarur, F., I998). Además, en las excavaciones de El Hato, en niveles con cerámica Lourdes, se encontró un cincel probablemente utilizado para trabajar metales (Zarur, F., I998, p. 85). Y el caso de El Hato no es único: otro asentamiento del Período Medio, ubicado donde hoy está el pueblo de Inzá, también tiene antecedentes en el Período Temprano 3.

\section{Período Medio}

C E IDENTIFICA A PARTIR DE LA CERÁMICA GUACAS y ES, DE LEJOS, EL PERÍODO con mejor datación en Tierradentro. A él corresponde una fecha de $630+/-82$ d. C. reportada por A. Chaves y M. Puerta (I980, p. 73), así como otras más obtenidas por el Proyecto: 125 +/- 260 d. C. (A-8883) y $190+/-55$ d. C. (A-8887) de un basurero asociado a la producción de sal en el Plano de Segovia excavado por J. Blick (I996), así como 800 +/- 80 d. C. (Beta I04089), 960 +/- 50 d. C. (Beta IIII62) y I300 +/- 80 d. C. (Beta I04088), correspondientes a plataformas de vivienda en Inzá (Langebaek, C. H., 1998).

Este período se caracteriza por sus similitudes con los procesos identificados en el Alto Magdalena. Un cambio importante se refiere a un considerable aumento de población: de I80.7 se pasa a 494.9 hectáreas de ocupación, equivalente al 2.35\% del área de estudio, mientras el número de pruebas es de 595 en comparación con las I92 del Período Temprano 3. El crecimiento se reparte de una forma más homogénea, la población aumenta en la región de la Quebrada de San Andrés, pero también lo hace de forma sustancial en la cuenca del río Negro y del río Ullucos. Por otra parte, para este período es posible reconocer concentraciones de población. El Plano de Segovia está ahora ocupado casi en 
su totalidad. Además, se reconoce un incremento sostenido en el tamaño promedio de los sitios, tanto en la Quebrada de San Andrés como por fuera de ella (mapa 6). Asociados a viviendas de Inzá, se encontraron evidencias de Mabea sp., un árbol útil para hacer utensilios, un maíz de raza pequeña (Zea mays), fríjol (Phaseolus sp.), algarrobo (Prosopis sp.) que produce frutos comestibles y es útil en construcción y prácticas medicinales (Sánchez, C. A., 2000).

MAPA 6

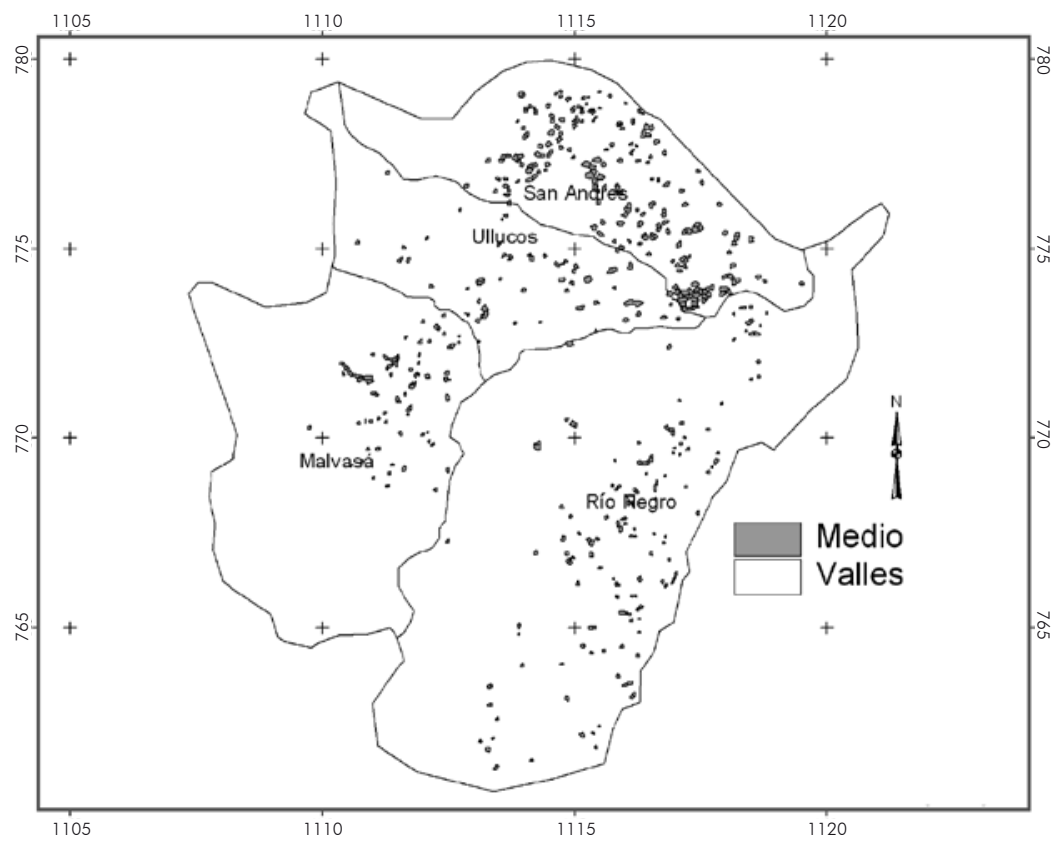

Distribución de asentamientos durante el Período Medio

El Período Medio corresponde al Período Clásico en San Agustín y el Valle de La Plata, en donde se asocia a la estatuaria, la construcción de montículos y la orfebrería (Duque, L., I963; Reichel-Dolmatoff, G., I97I; Drennan, R., I995). Ese es asimismo el caso en Tierradentro, aunque las correlaciones entre estatuaria y orfebrería con cerámica Guacas son tan buenas como las que hay con cerámica del Temprano 3. Por desgracia los sitios con estatuas en Tierradentro han sido muy alterados por guaqueros, así que no es fácil reconstruir sus características en detalle. Un inventario, lo más completo posible, de la estatuaria en la región fue iniciado por M. L. Sotomayor y M. V. Uribe (1987) y completado 
por el PAT (Cuéllar, A., 1995). En San Agustín, los conjuntos más espectaculares de estatuas y montículos se asocian a concentraciones de población que utilizaba cerámica Guacas (Drennan, R., I995); en Tierradentro lo mismo es cierto en una escala regional amplia: la mayor cantidad de estatuas se encuentra en la cuenca de San Andrés, que a su vez tuvo una amplia población durante el Período Medio. Pero dentro de esa cuenca lo mismo no parece cierto: los grupos más importantes de estatuas no siempre se relacionan con las más grandes densidades de población. Por ejemplo, el plano de Segovia tiene una gran concentración de población, pero evidencia de sólo una estatua e igual sucede con la aldea de Inzá donde las referencias de estatuas son escasas. No obstante, en El Hato y en El Tablón, ambos ubicados en la parte alta de la Quebrada de San Andrés, los conjuntos de estatuas coinciden con asentamientos del Período Medio (y también del Temprano 3).

Las estatuas de Tierradentro son por lo común más pequeñas que las de San Agustín. En general, se trata de representaciones antropomorfas pero hay diferencias interesantes de sitio a sitio. Una buena parte de las estatuas se encuentra en la parte alta de la cuenca de la Quebrada de San Andrés; un número considerable se encuentra en El Hato, y otras pocas en otros lugares, como Inzá y Viborá (Cuéllar, A., I995), aunque hay reportes aislados que sugieren su existencia en otros lugares (Rubiano, J. C., 1999). Pero además hay diferencias estilísticas, por ejemplo, la mayor parte de las estatuas con representaciones de pectorales provienen de El Tablón. En El Hato parece concentrarse la mayor diversidad, pues en ese lugar hay estatuas antropomorfas, zoomorfas y antropozoomorfas, así como estelas; aquí es donde se encuentran las estatuas más grandes y más elaboradas. Por cierto, una estatua encontrada en San Isidro confirma que al igual que en San Agustín las estatuas debieron estar pintadas (Cuéllar, A., I995).

En El Hato fue posible identificar montículos artificiales en un área donde también hay estatuaria (Zarur, F., 1998). El estado de dichos montículos es lamentable; todos han sido guaqueados y la gente local afirma que en ellos se ha hallado oro y cerámica. Sin embargo, de acuerdo con descripciones previas, se trataba de montículos funerarios asociados a enterramientos (Pérez de Barradas, J., I937a, p. I5). Aunque es dudoso que se tratara de estructuras idénticas a las de San Agustín (faltan por ejemplo "guardianes" monumentales), es probable que también sirvieran 
para sustentar ideológicamente el poder de ciertos personajes. Para tomar en cuenta en futuras interpretaciones sobre la estatuaria del lugar, la que se encuentra en El Hato incluye por lo menos una representación de vivienda, columnas con caras humanas y una serie de "saurios", muy diferentes a las grandes estatuas antropomorfas de El Tablón (Sotomayor, M. L. y M. V., Uribe, 1987, pp. 249-61), pero más parecidas a las de San Agustín (Cuéllar, A., I995).

En cuanto a la orfebrería, la evidencia para sugerir su asociación al Período Medio es más bien indirecta. En el Alto Magdalena la orfebrería no es demasiado frecuente y lo mismo sucede en Tierradentro. E. White (I934, p. 245) reporta la explotación de oro, en pequeñas cantidades, en la parte baja de la Quebrada de San Andrés, así que hay alguna materia prima para trabajar. Se sabe que los guaqueros han extraído objetos de metal de tumbas; incluso existen algunas referencias sobre probables sitios donde se producía orfebrería (Puerta, M., 2005, pp. 64-76). Algunos objetos de metal encontrados en tumbas tienen rasgos similares a la estatuaria (Pérez de Barradas, J., I937b; Duque, L., I979). Otros objetos parecen proceder de la región Calima y pertenecen al período Yotoco (Cardale de Schrimpff, M., et al., I992, p. II8), cuya cronología, calculada entre el o y el I20o d. C., coincide con la propuesta para el Período Medio en Tierradentro.

\section{Período Tardío}

STE CUENTA, POR AHORA, CON UNA SOLA FECHA CORRESPONDIENTE AL I640
+/- 50 (Beta II6373) asociada a una vasija con el borde doblado
hacia afuera y decoración ungular al parecer del tipo Califor-
nia Gris Pesado. Además de cerámica de este tipo se encuentra
alfarería Barranquilla y California, identificados por el Proyecto
Valle de la Plata. No es claro, sin embargo, si existen diferencias
cronológicas entre estos tipos, como se ha sugerido en el Valle
de la Plata (Drennan, R., 20oo, p. I27). El período, al igual que en
esta última región, se caracteriza por un aumento demográfico
continuado (se pasa de 494.9 a 75I hectáreas habitadas, lo que
implica una ocupación del 3.56\% del área investigada, y de 595 a
936 pruebas) que, sin embargo, no es tan dramático como el que
se dio entre el Temprano 3 y el Medio. Si bien siguen ocupadas
las aldeas de la Quebrada de San Andrés, durante el Período 
Tardío crecen concentraciones en otros lugares, como en Inzá y El Hato. Otro cambio es que la población empieza a incrementar en regiones antes desocupadas, como es el caso de las partes más altas de la cuenca de los ríos Ullucos y Malvasá (mapas 7 y 8).

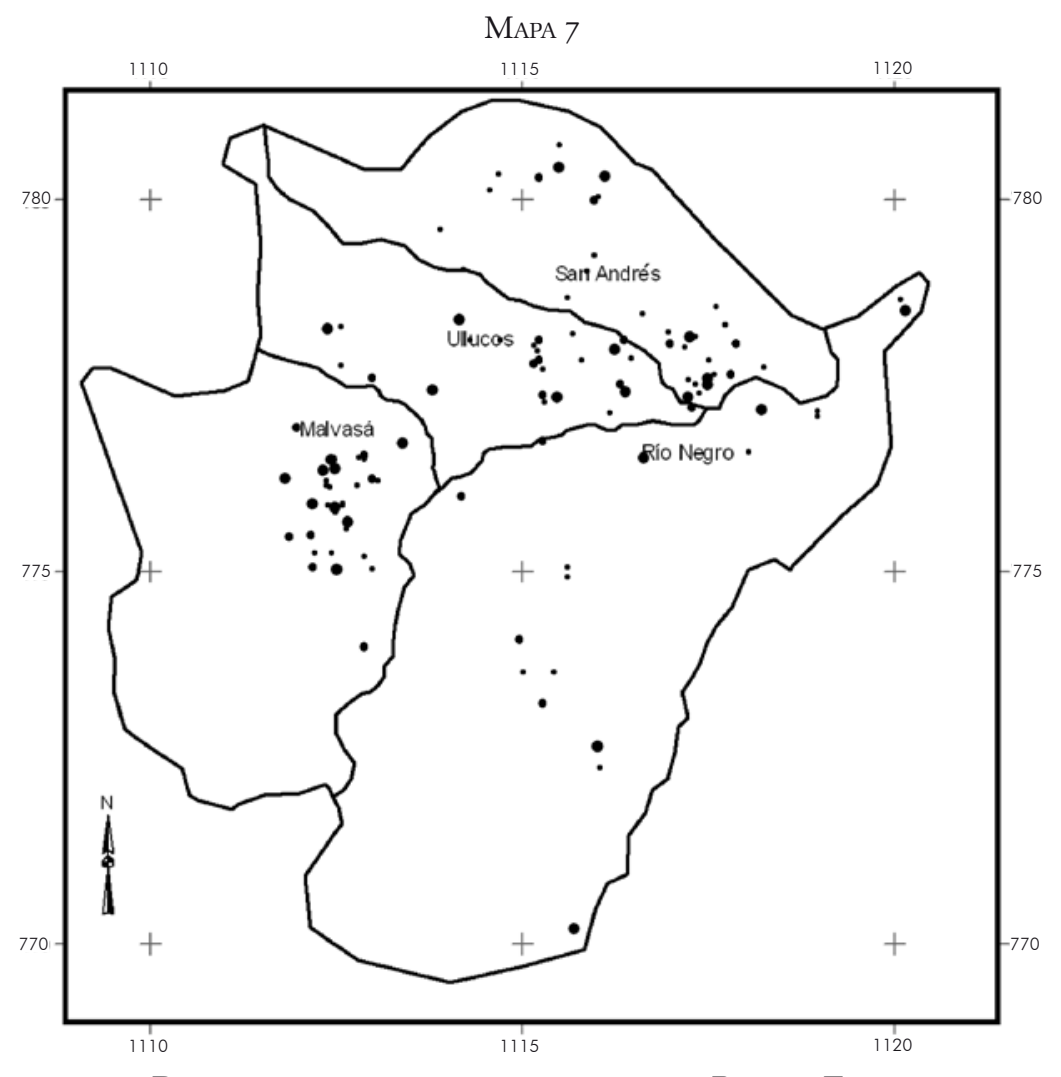

Distribución de asentamientos durante el Período Tardío

La información sobre el Período Tardío corresponde a las poblaciones que encontraron los españoles en el siglo XVI. Según J. Friede (I967), los nasa ocupaban la cuenca del río Páez y los cursos bajo y medio del río La Plata, pero los límites no son precisos. Lo cierto es que los documentos hablan de paeces, guanacas, pijaos y otros grupos. La diversidad cultural en la región quizás explique por qué Tierradentro ni siquiera figure como una "provincia", término con el que los españoles designaban regiones o pueblos que en líneas generales compartían aspectos culturales (Friede, J., 1967; Uribe, M. V., 1986). Según J. Rappaport (1982) existían tres 


\section{MAPA 8}
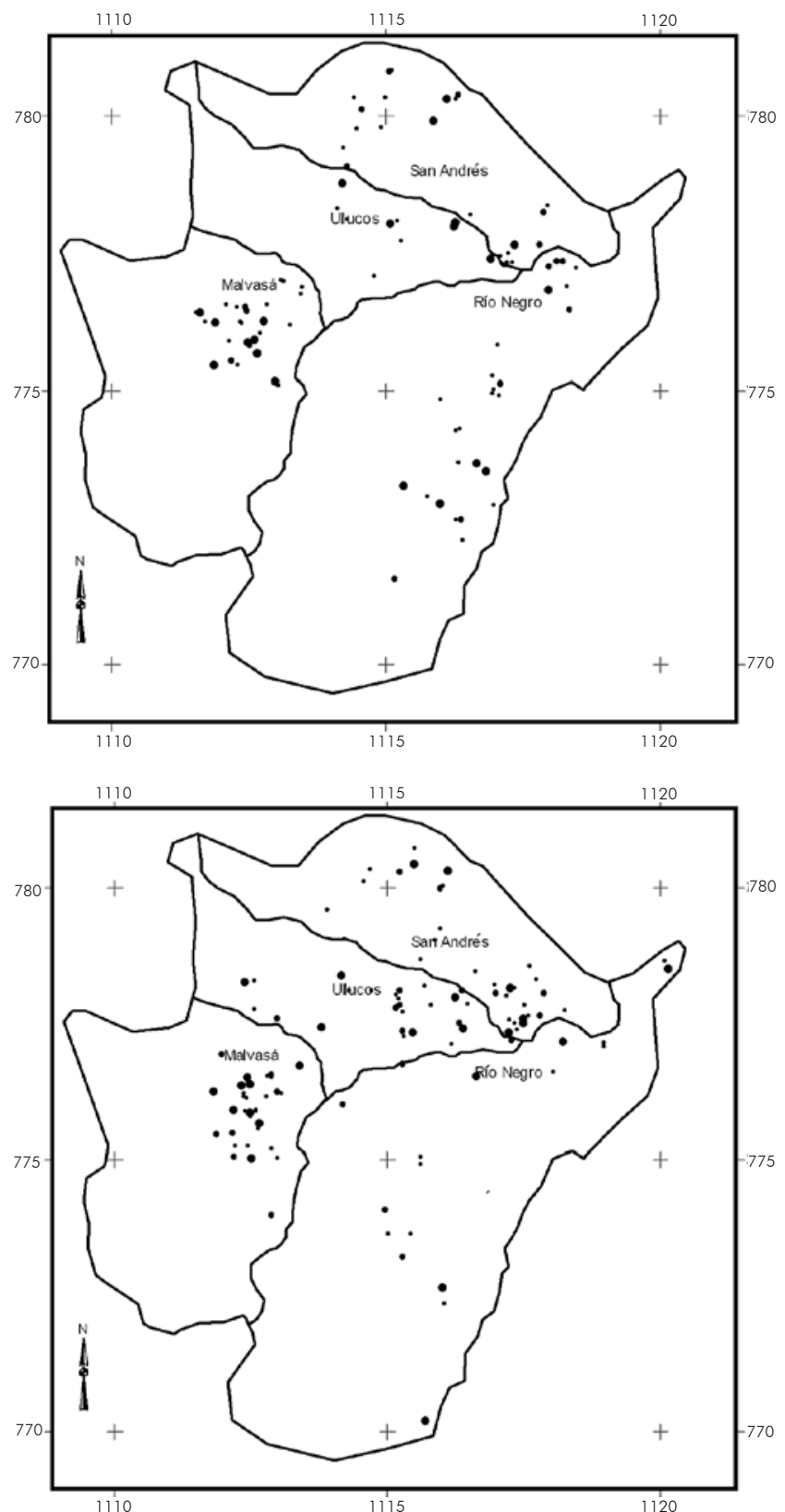

PRUEBAS CON DENSIDAD DE CERÁMICA POR ENCIMA DE UNA DESVIACIÓN ESTÁNDAR SOBRE LA MEDIA, PERÍODOS MEDIO Y TARDíO 
cacicazgos: Páez, al norte, Suyn en la cuenca del bajo Moras y Abirama, al sur. Cada uno tenía un amplio dominio territorial que le permitía acceder de manera autónoma a una gran variedad de productos. Algunos autores consideran que el liderazgo político era difuso (Findji, M. T. y Rojas, J. M., I985), pero que existía algún grado de dominio sobre líderes políticos de menor importancia, a veces llamados caciquillos (Rappaport, J., I982, p. 9I). En Páez se habla de que gobernaban cinco hermanos, el mayor de ellos el más importante. Al parecer, estos caciques no recibían tributo ni su poder se podía medir por el número de sujetos que tuvieran; por el contrario, debían actuar con generosidad, aunque como prerrogativas llevaran adornos especiales, precedieran ciertas ceremonias y tuvieran virtudes asociadas a sus conocimientos chamánicos (Rappaport, J., I982, pp. 95-96).

Como en San Agustín, muchos autores han especulado sobre la decadencia de las sociedades prehispánicas antes de la llegada de los españoles, cuando no de una discontinuidad entre la secuencia prehispánica y la población actual, a veces sin mayor evidencia, como discuten C. Gnecco y C. Hernández (2008). Sin embargo, los datos arqueológicos del Período Tardío sugieren cierto desarrollo de la desigualdad social. Aunque el poblamiento tardío es el más abundante en la región, no se asocia con evidencias de agricultura intensiva, que en el caso de San Agustín se interpretan como resultado de las demandas de una economía política más desarrollada (Sánchez, C., 2005). No obstante, un estudio llevado a cabo por J. R. Aparicio (1999) en ocho terrazas del Período Tardío de Inzá indica que algunas de ellas fueron mucho más grandes que las demás y, asimismo, que en las terrazas más extensas se encuentra una cerámica más elaborada, así como una mayor proporción de ollas y de fragmentos decorados. Lo anterior sugiere un importante desarrollo de la jerarquización en relación con la evidencia recolectada con respecto a viviendas del Período Medio.

\section{Período Moderno}

CORRESPONDE A lOS ASENTAMIENTOS POSTERIORES A LA CONQUISTA ESPAÑOla. En términos cronológicos abarca entre cerca de I600 d. C. hasta nuestros días. Una de las características más notorias es la de una ocupación muy poco densa. Esta es una situación típica de la mayor parte de las regiones de Colombia donde el 
período posterior a la Conquista se ha estudiado desde el punto de vista regional: de las 936 hectáreas de ocupación del último período prehispánico se pasa a sólo 88.8 , lo que significa que el porcentaje de área ocupada pasa del 3.34\% al 0.4\% (mapa 9). Se trata de la única parte de la secuencia donde se reconoce una baja de población. En contraste con la ocupación anterior, la vida en aldeas desaparece; excepto por las recientes fundaciones mestizas, la mayor parte de la población vive ahora en asentamientos dispersos, lo que en efecto se ha considerado una característica del patrón de poblamiento nasa (Trimborn, H., 1949, p. I30; Londoño, J., I955; Yanguez, J., I968, p. 23).

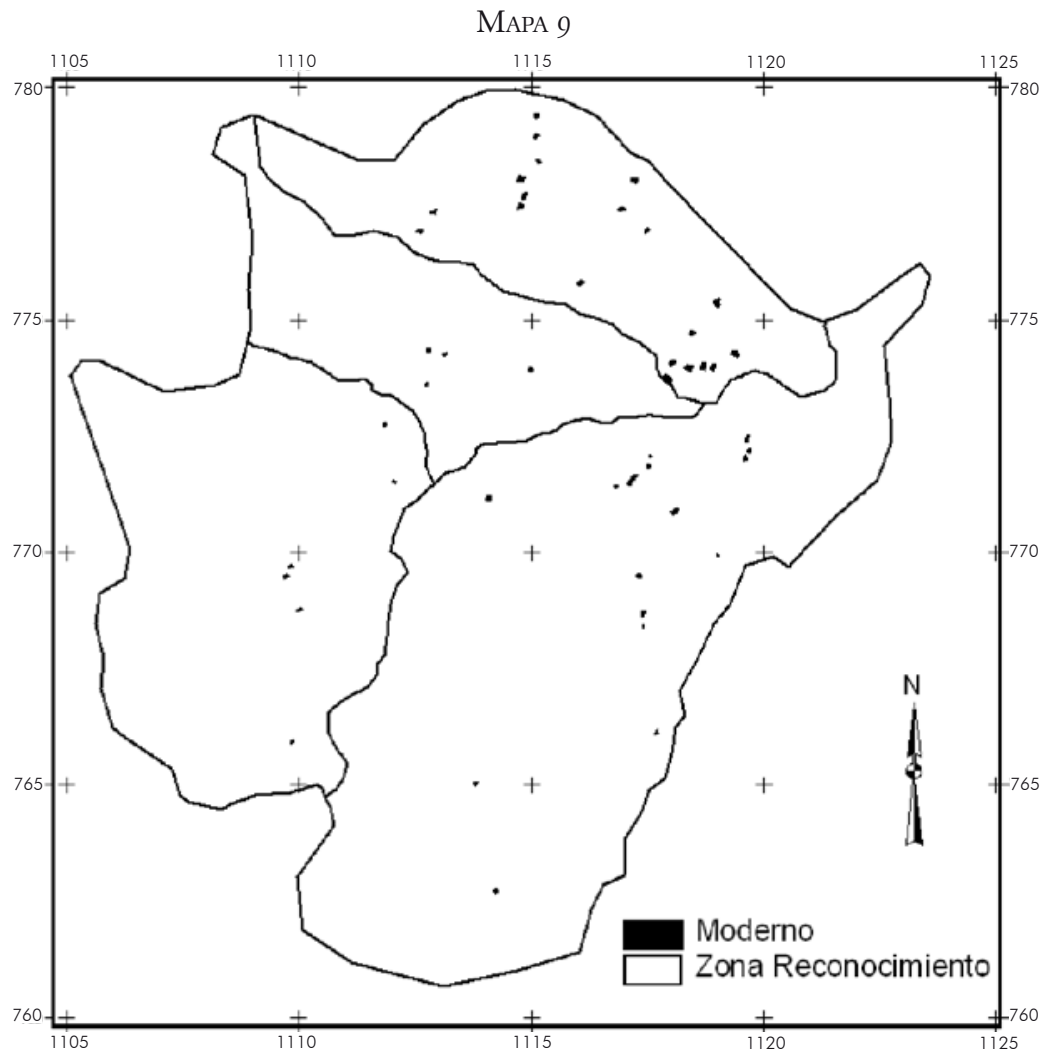

Distribución de asentamientos durante el Período Moderno

Es difícil tomar el patrón disperso contemporáneo como prueba de la discontinuidad de la secuencia de poblamiento en el área de estudio. A pesar de que con frecuencia se asume que los nasa provienen de afuera, no hay razón para descartar 
un poblamiento relativamente continuo en la región. Los nasa hablan una lengua que ha sido clasificada como independiente (Kaufman, T., I990) y algunos aspectos de su tradición oral, parentesco, plantas y drogas favoritas, favorecen la idea de vínculos con sociedades del Amazonas (Rappaport, J., I982, pp. I2O-4, I33). Vale la pena mencionar que recientes estudios genéticos (Yunis, J. J., et al., 200I) sugieren una relación entre los grupos nasa y grupos indígenas de la Amazonia. Sin embargo, estas relaciones no desmienten que la población nasa sea en buena parte descendiente de los ocupantes de Tierradentro durante el Período Tardío, puesto que los vínculos con las tierras bajas pueden ser remotos. En todo caso, los datos del reconocimiento regional indicarían una continuidad en el poblamiento a lo largo de siglos. Incluso, se debe destacar que las concentraciones de población actuales coinciden de forma notable con las aldeas desarrolladas en el Período Tardío. Tanto San Andrés de Pisimbalá como Segovia, Inzá y el Hato son pequeños pueblos o concentraciones indígenas o campesinas.

\section{DINÁMICA DEMOGRÁFICA}

Y DISTRIBUCIÓN DE LA POBLACIÓN

A METODOlOGía DE MUESTREO SISTEMÁtiCO REGIONAL PRODUCE DATOS sobre la distribución de la población en cada período arqueoló-gico y, además, dos indicadores gruesos que sirven para estimar cambios demográficos: cantidad y densidad de cerámica y área de ocupación. Por supuesto, la cantidad y densidad utilizadas por las unidades domésticas de cada período dependen de muchos factores, como duración del período, intensidad de la ocupación, calidad de la cerámica y prácticas culturales. Sin embargo, la metodología sistemática y el tamaño de la muestra garantizan que esta proveniente de cientos de pruebas de pala contiene suficiente variación, que es capaz de producir estadísticas robustas que a la vez permiten la caracterización del tamaño y distribución de unidades residenciales en la región de Tierradentro (Drennan, R., I985).

Al tomar en cuenta sólo la frecuencia de cerámica, la secuencia corresponde a un continuo incremento de población en épocas prehispánicas, siendo los aumentos más abruptos los que 
corresponden al Período Temprano 3 y al Período Tardío (gráfico I). No obstante, estas variaciones en frecuencia están distorsionadas por las grandes diferencias en duración de los períodos, en especial en el caso del Período Medio que alcanza los I.200 años. Si se corrige la información de acuerdo con la duración de los períodos y cada uno de ellos se separa por intervalos equivalentes, el efecto es algo diferente: se mantiene la impresión de que los dos cambios más abruptos están determinados por los aumentos en Temprano 3 y Tardío, pero se encuentra una disminución del índice en el Período Medio (gráfico 2).

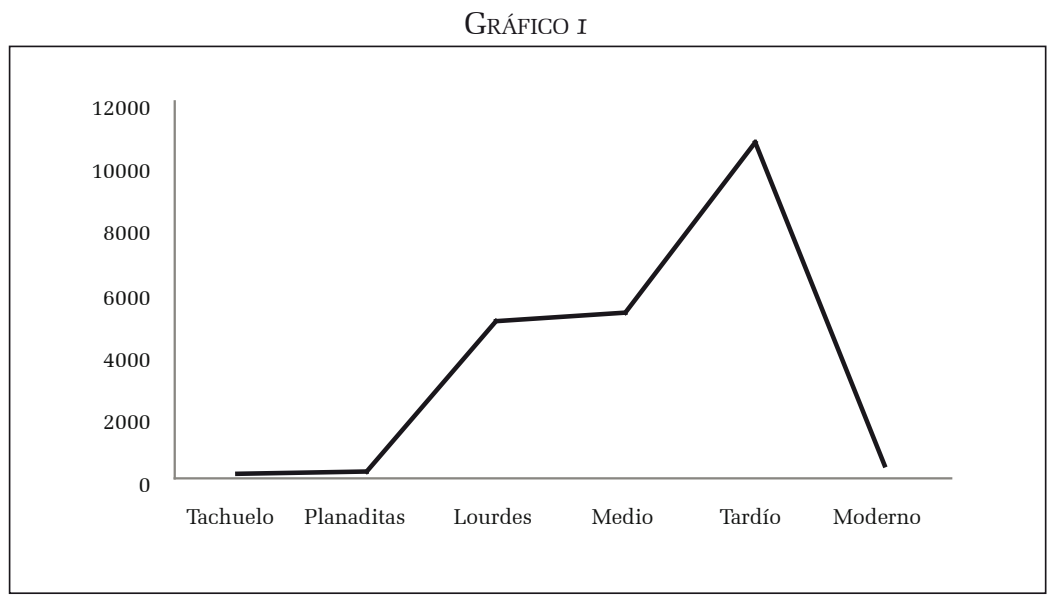

FRECUENCIA DE FRAGMENTOS DE CERÁMICA POR PERÍODO

GRÁFICO 2

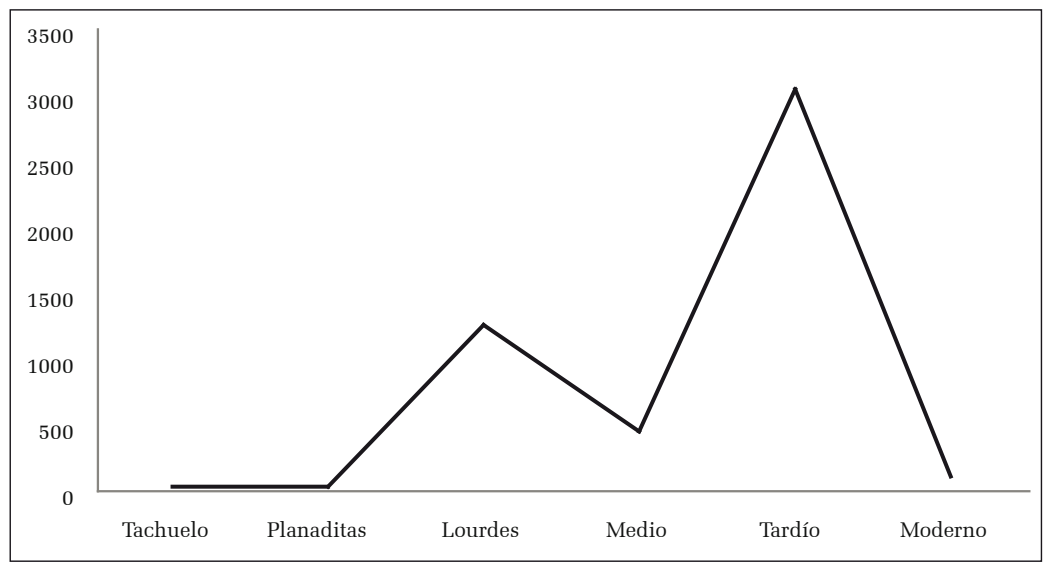

RELACIÓN FRAGMENTOS DE CERÁMICA/SIGLO 
El área ocupada durante la secuencia puede verse afectada por la diferencia en duración de los períodos, por ejemplo: durante el Temprano es de 353.92, para un total de I.000 años. Esta cifra es equivalente a las 500.4 hectáreas del Medio, que corresponden a I.300 años. Con el fin de corregir estas distorsiones, la parte inferior de la tabla 2 muestra los índices de población relativa según la duración del período (xioo/duración en años) y el correspondiente cambio porcentual. Con la intención de minimizar las distorsiones producidas por las diferencias en los períodos, la frecuencia de cerámica y el área de ocupación, estas se pueden condensar en un índice de densidad de fragmentos de cerámica por metro cúbico por área, si aceptamos que todas las muestras provienen de pruebas de pala estandarizadas (lo que se aplica a Tierradentro). Este índice permite no tener en cuenta las características de la muestra sino que posibilita hacer comparaciones entre múltiples regiones (Drennan, R., et al., 2003, pp. 157-I58; Dever, A., en preparación). El Índice de Área-Densidad se refiere a la sumatoria de lotes (pruebas) con X hectárea con una ocupación de Y densidad, asumiendo una densidad de $0.16 \mathrm{~m}^{2}$ por prueba. Los resultados del índice se resumen en la tabla 3 .

TABLA 2.

\begin{tabular}{|l|c|r|r|r|c|}
\hline & $\begin{array}{c}\text { Duración } \\
\text { en siglos }\end{array}$ & $\begin{array}{c}\text { Siglos como } \\
\text { unidad }\end{array}$ & $\begin{array}{c}\text { Cerámica/ } \\
\text { Siglo }\end{array}$ & $\begin{array}{c}\text { Índice } \\
\text { Área } \\
\text { Densidad/ } \\
\text { Siglos }\end{array}$ & $\begin{array}{c}\text { Índice } \\
\text { Densidad- } \\
\text { Área }\end{array}$ \\
\hline Moderno & 3.5 & 0.875 & 95.14 & 2.26 & 7.89 \\
\hline Tardío & 3.5 & 0.875 & 3039.14 & 72.54 & 253.90 \\
\hline Medio & 12 & 3 & 431.92 & 8.75 & 104.99 \\
\hline Temprano 3 & 4 & 1 & 1238.25 & 6.8 & 27.21 \\
\hline Temprano 2 & 6 & 1.5 & 21.5 & 0.96 & 5.78 \\
\hline Temprano 1 & 4 & 1 & 13 & 0.17 & 0.70 \\
\hline
\end{tabular}

CÁlCUlos dE DENSIDAD DE FRAGMENTOS DE CERÁMICA POR METRO CÚBICO POR ÁREA 


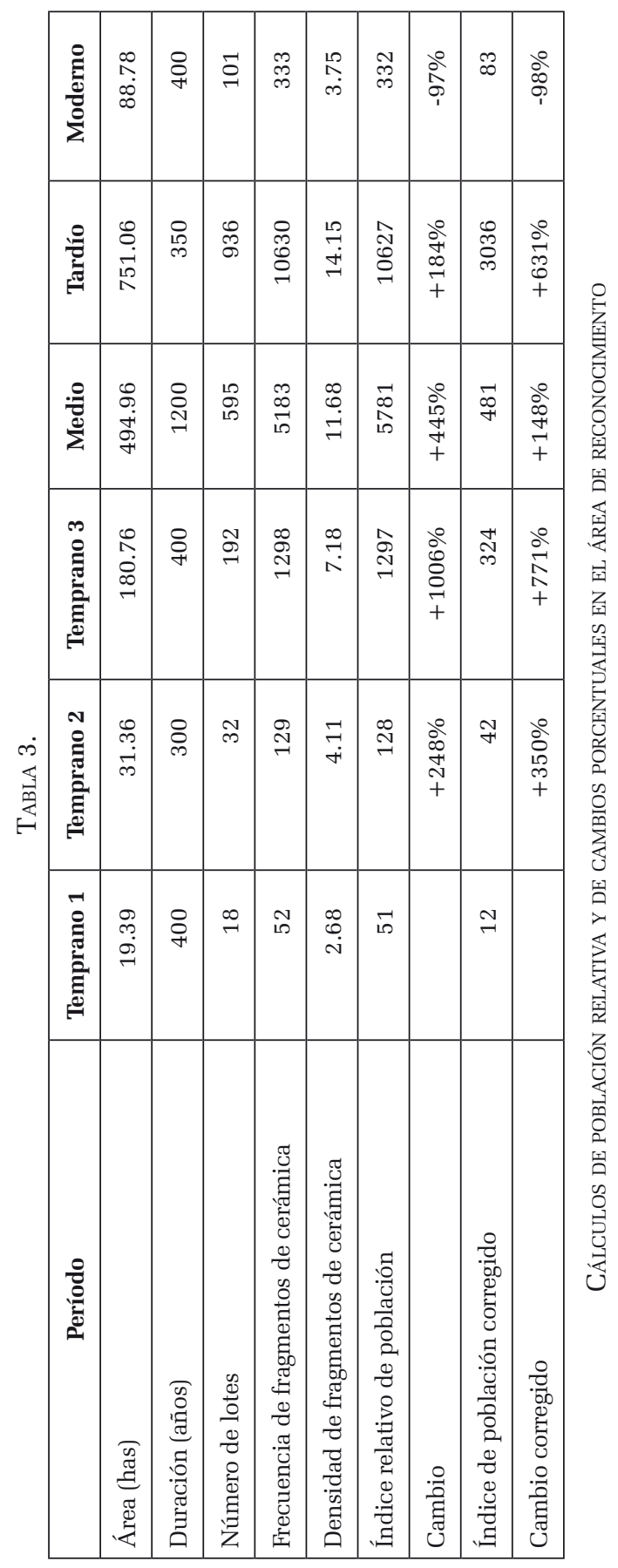


De acuerdo con los resultados de este análisis, la secuencia se caracteriza por un continuo proceso de aumento de población. Por lo pronto, se puede hablar de dos cambios abruptos en el área ocupada, el más notable corresponde al Período Temprano 3. El incremento es menos grande en el Período Medio, pero vuelve a acentuarse en el Período Tardío. Otra importante transformación es la enorme disminución demográfica después de la llegada de los españoles. De hecho, después de la Conquista el nivel de población se habría reducido a niveles por debajo del Período Temprano 3, es decir, entre el 300 a. C. y el Ioo d. C.

Las investigaciones en la aldea de Inzá permiten conocer en detalle algunos aspectos adicionales de la dinámica de población desde la perspectiva de un asentamiento en particular. Los sondeos realizados en los aterrazamientos visibles en ese lugar encontraron 27 terrazas que sólo contenían cerámica del Período Medio y 32 con sólo cerámica del Período Tardío (foto 3). El tamaño promedio de las primeras es 50\% menos que el de las segundas, lo que sugiere que el tamaño de las familias de la última ocupación prehispánica era más grande que en el período anterior (gráfico 3). Además, vale la pena anotar que las terrazas de vivienda excavadas por D. A. Astudillo (2008, pp. 87-88) en otros lugares de Tierradentro tienen más cerámica tardía que del Período Medio.

Foto 3

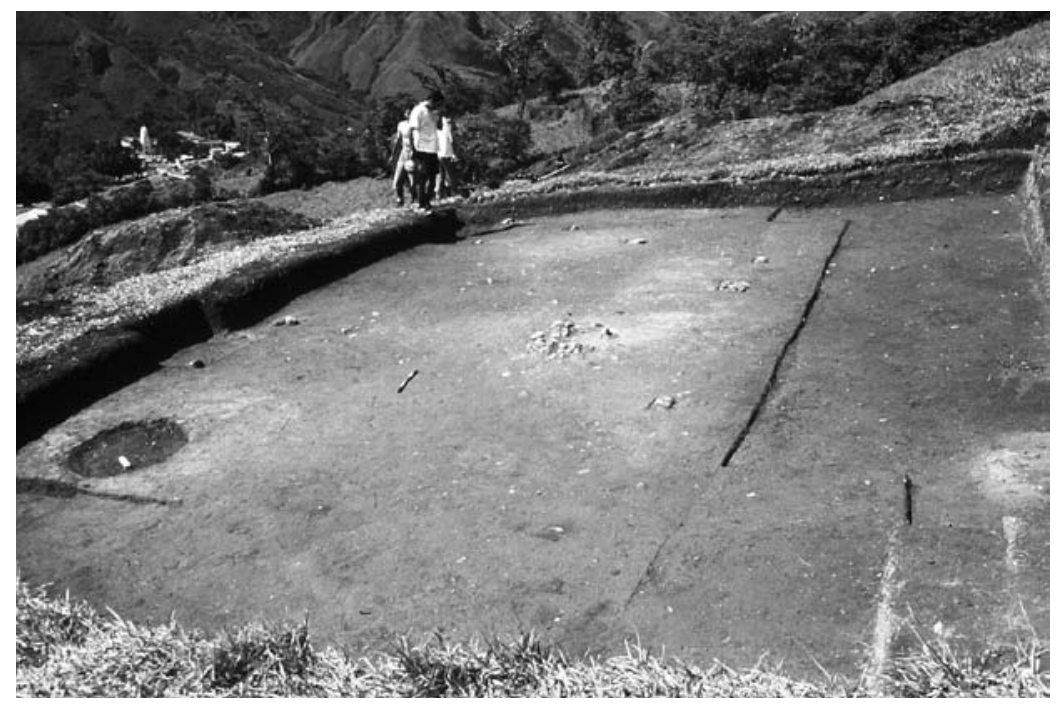

Excavación de plataforma de vivienda en el asentamiento de Inzá 
GRÁFICO 3

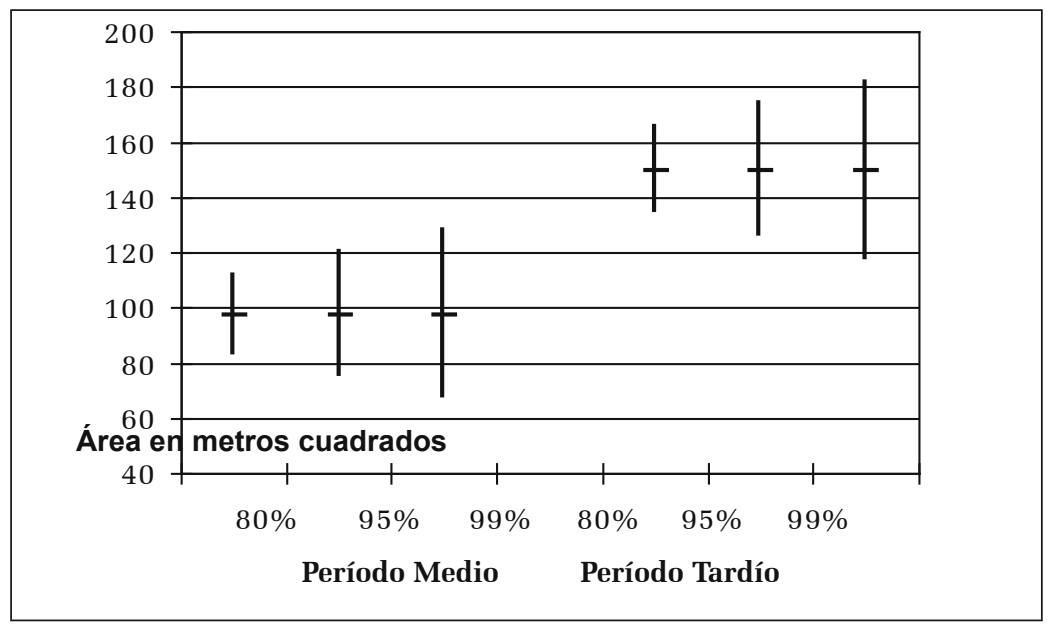

COMPARACIÓN DE TAMAÑO DE PLATAFORMAS DE LOS PERÍODOS

\section{MEDIO Y TARDío EN INZÁ}

Un aspecto importante es que la dinámica de población no fue uniforme por completo a lo largo de la secuencia. Durante buena parte de ella, la región de San Andrés concentró parte sustancial de la población, aunque debe resaltarse la excepción de la ocupación Temprano 2, cuando la de Ullucos alcanza a superar la de San Andrés, así como la pérdida de protagonismo de la ocupación en esta última región durante el Período Tardío; tendencia que viene del Período Medio y que se contrarresta con una creciente importancia del poblamiento en Malvasá y río Negro (tabla 4). En todo caso, la región de San Andrés tiene el mayor porcentaje de área ocupada durante el Temprano 3 y Medio, justo cuando se desarrollan las primeras evidencias de monumentalidad en Tierradentro (tabla 4).

TABLA 4

\begin{tabular}{|l|c|c|c|c|}
\hline \multicolumn{1}{|c|}{ Período } & $\begin{array}{c}\text { Malvasá } \\
(\mathbf{2 5 . 4 \%} \text { del } \\
\text { área) }\end{array}$ & $\begin{array}{c}\text { Ullucos } \\
(\mathbf{1 3 . 5 \%} \text { del } \\
\text { área) }\end{array}$ & $\begin{array}{c}\text { San Andrés } \\
\text { (17.3\% del } \\
\text { área) }\end{array}$ & $\begin{array}{c}\text { Río Negro } \\
\text { (43.8\% del } \\
\text { área) }\end{array}$ \\
\hline Tardío & $22.6 \%$ & $16.4 \%$ & $37.1 \%$ & $23.9 \%$ \\
\hline Medio & $12.8 \%$ & $12.1 \%$ & $52.3 \%$ & $22.8 \%$ \\
\hline Temprano 3 & $13.1 \%$ & $12.2 \%$ & $68.7 \%$ & $6.8 \%$ \\
\hline Temprano 2 & $10.4 \%$ & $48,0 \%$ & $37.3 \%$ & $4.4 \%$ \\
\hline Temprano 1 & $0 \%$ & $36.3 \%$ & $45.9 \%$ & $17.7 \%$ \\
\hline
\end{tabular}

ÁREA DE OCUPACIÓN EN CADA UNA DE LAS SUBREGIONES DEL ÁREA DE ESTUDIO POR PERÍODO 
Para hacerse una idea de lo que significan los resultados obtenidos por el PAT en términos demográficos, es útil hacer algunas comparaciones. Por el momento, una se refiere al Alto Magdalena, donde se han hecho esfuerzos significativos por estudiar el tema. En esa región las estrategias de reconocimiento fueron más o menos detalladas, según se trate de las regiones occidental (más alta en msnm) u oriental (más baja en msnm), pero pese a que en esta última la estrategia de estudio favorece cifras más altas, no es claro que su población fue más abundante a lo largo de toda la secuencia en la parte occidental y alta que en la región oriental y baja (Drennan, R., 2000). Los resultados del PAT son más fáciles de contrastar con los obtenidos en la parte oriental, que corresponde a la parte baja del río Páez. Aún así es fácil concluir que la población fue menor que en la parte occidental del estudio en el Valle de La Plata, pero mayor que en la parte más baja. Globalmente, el porcentaje de área ocupada durante el Período Temprano en esta última región es del 3.2\%, muy por encima del porcentaje de las subdivisiones de ese período en nuestro estudio o incluso de la suma de las tres; en lo que atañe al Período Medio el porcentaje de área ocupada en La Plata es del 6.5\%, mientras en Tierradentro es del 2.35\%, e igual contraste se puede señalar para el Período Tardío (Drennan, R., et al., I99I). Indicadores gruesos de población absoluta para un área de 187 $\mathrm{km}^{2}$ reconocida alrededor de La Argentina en el Alto Magdalena, basados en una población de entre cinco y diez habitantes por hectárea ocupada, indicaría entre 6.500 y 13.000 individuos para el Período Tardío (Drennan, R., et al., I99I, p. 3I3), mientras que para el mismo período, pero para un área algo más grande (2II $\mathrm{km}^{2}$ ), el mismo ejercicio en Tierradentro implicaría una población entre 4.506 y 7.5IO personas. Por otra parte, mientras en la parte más alta y occidental del estudio realizado en el Valle de la Plata la ocupación del Período Medio equivale al 8\%, y en la zona oriental y más baja es del I.7\%, en el caso de Tierradentro el porcentaje es de $2.35 \%$.

Un paralelo interesente se refiere a la población prehispánica en relación con la ocupación contemporánea de Tierradentro. La tabla 5 presenta los rangos de población absoluta y la correspondiente densidad por $\mathrm{km}^{2}$ en el área de reconocimiento. Asimismo, se incluyen los estimativos relativos a la densidad de población en Inzá (20.4 por $\mathrm{km}^{2}$ ) y en Páez (I3.I por $\mathrm{km}^{2}$ ), de acuerdo con E. Sevilla (I976, p. I8). Como se puede apreciar la densidad de pobla- 
ción incluso hoy en día, que incluye blancos, afrodescendientes y mestizos, además de la nasa, es inferior a la que se calcula para el Período Tardío y cae dentro del rango estimado para el Período Medio. La población contemporánea de la región de estudio sólo sería superior a la de los períodos Temprano.

TABLA 5

\begin{tabular}{|l|c|c|c|c|c|}
\hline & Temprano 1 & Temprano 2 & Temprano 3 & Medio & Tardío \\
\hline $\begin{array}{l}\text { Población } \\
\text { absoluta }\end{array}$ & $96-194$ & $156-313$ & $903-1807$ & $2474-4949$ & $3755-7510$ \\
\hline $\begin{array}{l}\text { Densidad } \\
\text { por km² }\end{array}$ & $.5-1$ & $.7-1.5$ & $4.3-8.5$ & $11.72-23.5$ & $18-35.6$ \\
\hline
\end{tabular}

CÁLCULOS DE POBLACIÓN ABSOLUTA POR PERÍODO Y DENSIDAD POR KMำ

\section{DistribuCióN DE LA POBLACIÓN Y SUELOS}

Lla PAT ASUME QUE LA AGRICULTURA ERA UN ASPECTO FUNDAMENTAL DE la economía de los grupos alfareros desde la ocupación más -temprana de la que encuentra evidencia y que, por lo tanto, el estudio de la relación entre los asentamientos humanos y los suelos es determinante para entender la dinámica de cambio social en Tierradentro. Con el fin de estudiar dicha relación, se siguieron dos estrategias diferentes basadas en el estudio de las condiciones naturales de los suelos para fines agrícolas.

Uno de los análisis realizados por el PAT se apoyó en el estudio a cargo de B. Jiménez y la asesoría de P. Botero (Jiménez, B., I995), que diferenció tres categorías de suelos de acuerdo con sus condiciones fisicoquímicas y de pendiente (mapa Io). Por otra parte, se hicieron exámenes más sofisticados basados en la distribución de suelos en cada una de las cuencas estudiadas y la consideración de cinco categorías de suelos en vez de tres, dando mayor importancia a las características fisicoquímicas de los suelos que a la pendiente (mapa II). La primera aproximación da pistas interesantes de la relación entre la distribución humana y algunas características muy generales del paisaje, aunque tiene limitaciones. El criterio de pendiente es útil para agricultura tecnificada pero no fue una limitante en el pasado. Aún hoy zonas relativamente inclinadas, no aptas para agricultura mecanizada, son productivas y se explotan. No obstante, el tema de la pendiente no se puede despreciar tan fácil. En Tierradentro las regiones 
más empinadas se concentran entre los 2.000 y $3.000 \mathrm{msnm}$, y aunque ello no impide la agricultura en alturas por encima de los 2.000 msnm, ni la concentración de población, hoy los indígenas nasa y los campesinos prefieren sembrar en las tierras fértiles y menos inclinadas, tanto el maíz, como el fríjol y la papa (Sanabria, O. L., 200I, pp. 4I, 59, 62-63). La segunda aproximación basada en cinco categorías de suelos, discrimina mejor suelos que son adecuados para la agricultura tradicional aunque sean algo inclinados para la mecanizada. En todo caso, independiente de cuál es la estrategia más apropiada, las conclusiones más interesantes surgen de su comparación.

MAPA IO

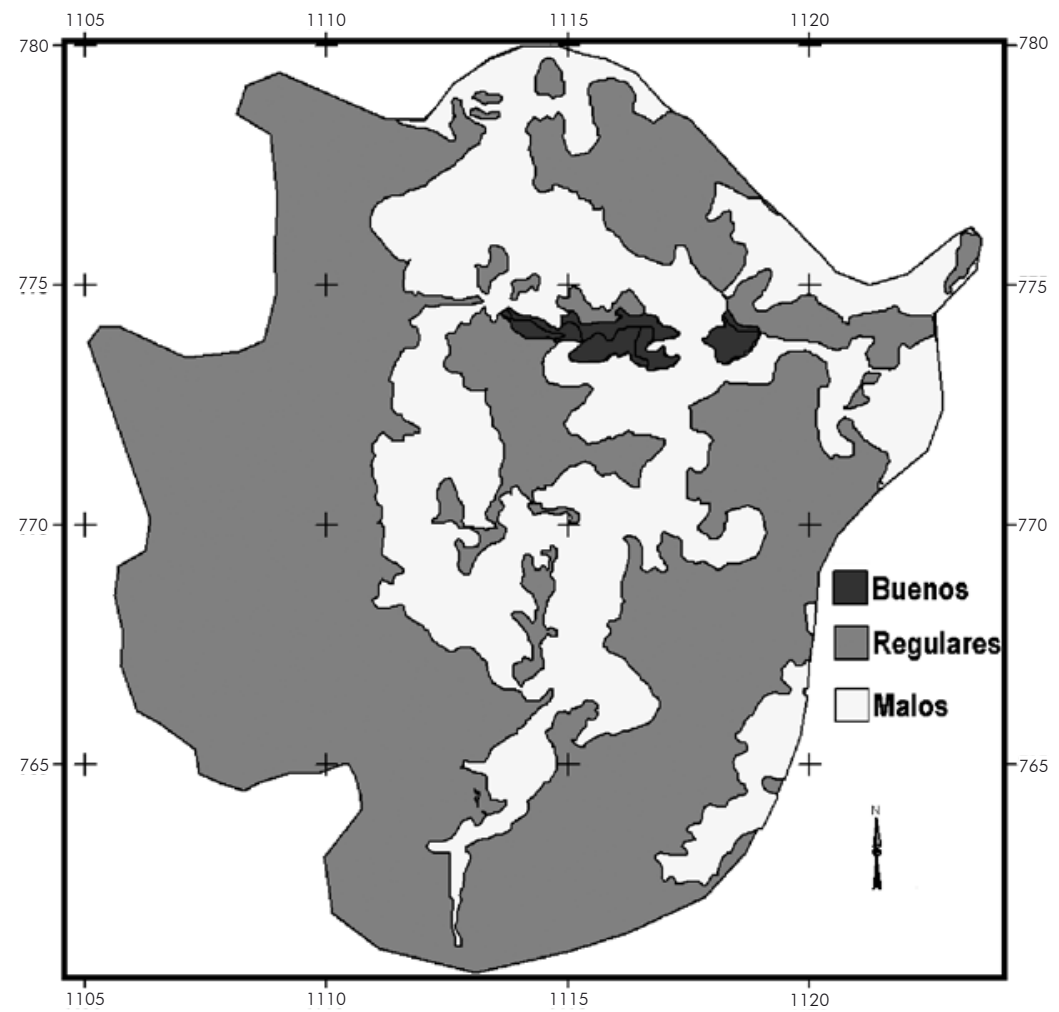

Clasificación de suelos de Tierradentro en tres categorías. Clase i: alta PRODUCTIVIDAD INDEPENDIENTEMENTE DE LA PENDIENTE. CLASE 2: PRODUCTIVIDAD LIMITADA POR ARCILLAS. ClaSe 3: LIMITANTE ARCILLAS Y ROCA CON PH BAJOS. CLASE 4: LIMITANTE SUELOS POCO PROFUNDOS CON PENDIENTES FUERTES. CLASE 5: PENDIENTES MUY FUERTES O ROCA. 


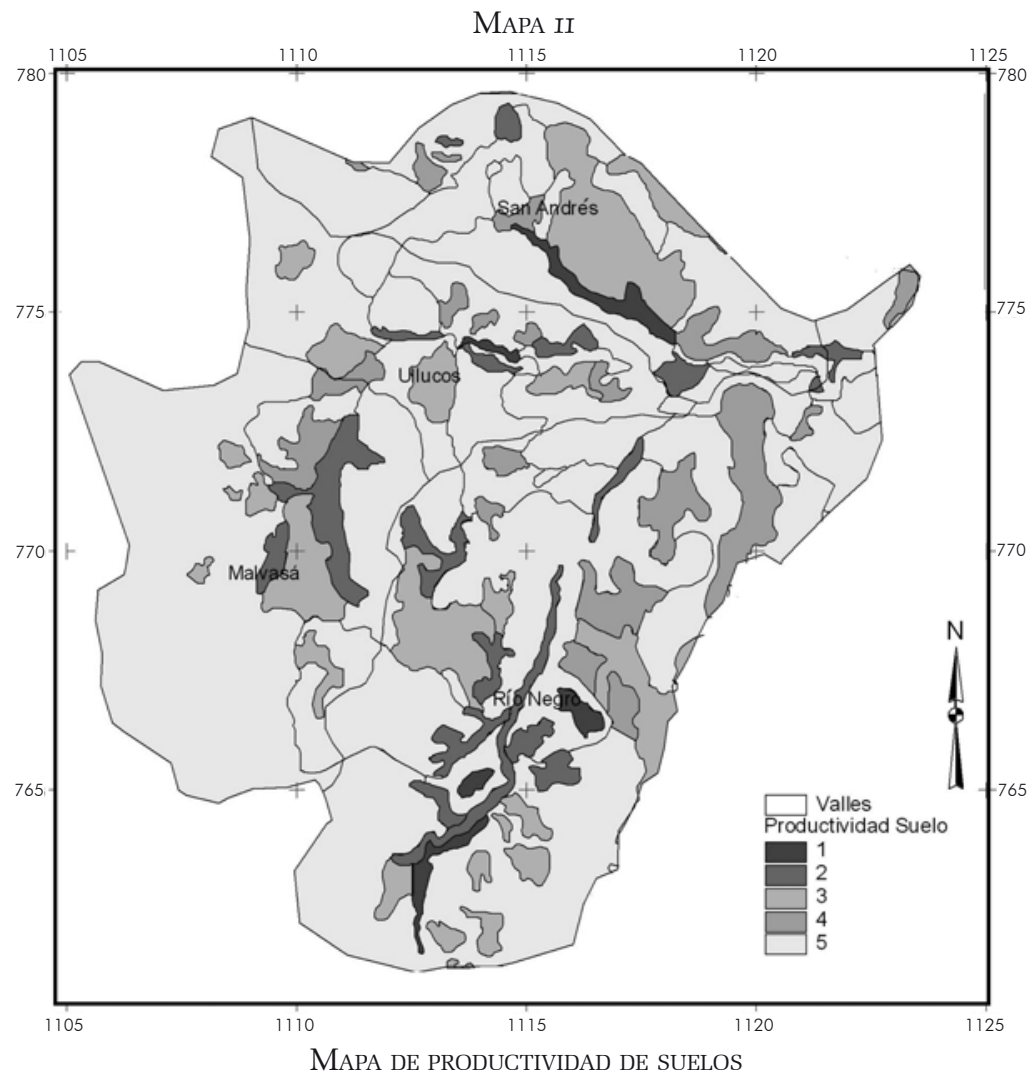

Según la primera aproximación, durante el Período Temprano se da progresivamente una tendencia a ocupar cada vez una proporción más grande de tierras óptimas para la agricultura: de un 35.I\% se llega a un $59.4 \%$ de asentamientos directamente ubicados sobre esa clase de suelos (tabla 6). Al mismo tiempo, la proporción de asentamientos ubicada sobre suelos malos es de ০\% en el Período Temprano I pero luego pasa a ser del I6y I3.9\% en los períodos Temprano 2 y Temprano 3. Esta información parece repetirse de forma sistemática en los diversos estudios regionales hasta ahora realizados, donde la población de los períodos más tempranos ocupa las tierras menos riesgosas para la agricultura (Langebaek, C. H. y Dever, A., 2000; Drennan, R., 2000, p. 62). La tendencia a que la gente ocupara cada vez con mayor interés suelos de óptima calidad se revierte en el Período Medio, aquel correspondiente a la estatuaria, orfebrería espectacular y construcción de montículos. Se pasa de un 59.4\% de asentamientos sobre tierras óptimas en 
el Período Temprano 3 a un 49.6\% durante el Medio, mientras el porcentaje de asentamientos ubicados sobre las peores tierras pasa del $13.9 \%$ al 21.I\%. Lo anterior se modifica en los períodos Tardío y Moderno. Por ejemplo, el 87.8\% de la población del último período prehispánico ocupó tierras óptimas, mientras tan sólo el 3.7\% se estableció sobre malas. Para el Período Moderno la relación es clara: el Ioo\% de la población vivió sobre los mejores suelos para llevar a cabo prácticas agrícolas.

TABLA 6

\begin{tabular}{|l|c|c|r|r|r|r|r|}
\hline \multicolumn{1}{|c|}{ Período } & $\begin{array}{c}\text { Suelos 1 } \\
\text { (pobres) }\end{array}$ & $\begin{array}{c}\text { Suelos 2 } \\
\text { (regulares) }\end{array}$ & $\begin{array}{c}\text { Suelos 3 } \\
\text { (buenos) }\end{array}$ & \% 1 & \% 2 & \% 3 & Total \\
\hline Moderno & - & - & 116.3 & - & - & $100.0 \%$ & 116.3 \\
\hline Tardío & 4.9 & 11.2 & 116.0 & $3.7 \%$ & $8.5 \%$ & $87.8 \%$ & 132.1 \\
\hline Medio & 70.7 & 98.0 & 166.3 & $21.1 \%$ & $29.3 \%$ & $49.6 \%$ & 335.0 \\
\hline Temprano 3 & 16.8 & 32.2 & 71.7 & $13.9 \%$ & $26.7 \%$ & $59.4 \%$ & 120.7 \\
\hline Temprano 2 & 13.7 & 22.6 & 49.2 & $16.0 \%$ & $26.4 \%$ & $57.5 \%$ & 85.5 \\
\hline Temprano 1 & - & 13.3 & 7.2 & - & $64.9 \%$ & $35.1 \%$ & 20.5 \\
\hline
\end{tabular}

ÁREA DE ASENTAMIENTO SOBRE TIPO DE SUELO POR PERÍODO DE OCUPACIÓN

Los resultados anteriores muestran un dato interesante: la mejor correlación entre suelos buenos para la agricultura, un recurso que asumimos fue preciado, se da justo antes y después del período durante el que se supone se dio el apogeo de la elaboración de estatuas y montículos, pero durante el período mismo de auge de la estatuaria, la orfebrería y la construcción de montículos, la correlación es la más pobre de toda la secuencia. En estas condiciones, parece dudoso que el acceso a suelos fértiles fuera un aspecto determinante de la diferenciación social, al menos a nivel regional.

Con respecto al análisis de la distribución de la población de acuerdo con la clasificación de suelos en cinco categorías, una conclusión muy general se puede apreciar si se analiza la distribución de la población por valle (tabla 7). En Tierradentro los valles tienen características diferentes. La región de San Andrés se caracteriza por una alta densidad de poblamiento a lo largo de la secuencia, que concentra la mayor parte de los suelos fértiles del área de estudio y además tiene el promedio de pluviosidad anual más alto (Guhl, A., I996) (mapa I2). Pero la situación parece más compleja. Si bien la región de San Andrés, pese a su tamaño comparativamente reducido, concentra el nada despreciable $42.7 \%$ 
de los suelos óptimos (categoría I), la región de río Negro no sólo la supera en ese sentido con un 50.3\%, sino que además lo hace, y mucho, con respecto a las categorías de suelos 2 y 3 . La región de río Negro concentra el 50.9\% de los suelos de categoría 2 y el $44.2 \%$ de suelos de categoría 3. Por supuesto, se puede afirmar que las consideraciones de productividad pudieron ser un factor importante para explicar por qué las regiones de Malvasá y Ullucos tuvieron menor poblamiento que San Andrés a lo largo de la secuencia, pero lo cierto es que la alta proporción de suelos adecuados para la agricultura en la región de río Negro no se correlaciona con porcentajes de población considerable a nivel regional. La proporción de gente que se concentra en río Negro es muy baja; incluso cuando alcanza su pico más alto, durante el Período Tardío, apenas concentra el 23.9\% de la población, lejos de San Andrés e incluso de Malvasá, región que no tiene suelos de la categoría I.

TABLA 7

\begin{tabular}{|l|r|r|r|r|}
\hline \multicolumn{1}{|c|}{ Categoría suelo } & Malvasá & Ullucos & San Andrés & Río Negro \\
\hline 1 Alta productividad & $7.0 \%$ & $0 \%$ & $42.7 \%$ & $50.3 \%$ \\
\hline 2 & $8.2 \%$ & $29.2 \%$ & $11.7 \%$ & $50.9 \%$ \\
\hline 3 & $13.8 \%$ & $17.0 \%$ & $25.0 \%$ & $44.2 \%$ \\
\hline 4 & $11.8 \%$ & $9.2 \%$ & $15.0 \%$ & $64.0 \%$ \\
\hline 5 Baja productividad & $13.4 \%$ & $26.2 \%$ & $15.0 \%$ & $45.4 \%$ \\
\hline
\end{tabular}

DisTRIBUCIÓN DE CATEGORÍAS DE SUELO EN LAS DIFERENTES SUBREGIONES ESTUDIADAS

Una prueba estadística de independencia $\left(\mathrm{Chi}^{2}\right)$ orientada a la distribución de la población en los suelos clasificados en cinco categorías mostró que sólo durante el período Temprano 3 la ubicación de asentamientos se alejó fuerte y significativamente de un patrón similar a la distribución natural de suelos. Aun cuando hay una proporción alta de tipos I y 2 en el territorio estudiado, la forma como se distribuyó la gente no siguió esta tendencia (tipos I y 2: $\mathrm{V}=0.57, \mathrm{P}=0.1060)$. La "anomalía" es fuerte con respecto a los suelos tipo 2 ( $\mathrm{V}=0.66, \mathrm{P}=0.1663)$, que son de alta productividad. Esto muestra que la población no vivió cerca de los suelos más productivos sino que su patrón de asentamiento estuvo motivado por otras consideraciones. Otra forma de ver este cambio es por medio del porcentaje de las pruebas de cada período que también tiene material del período anterior (tabla 8). Por ejemplo, mientras 9.77\% de las pruebas con material del Temprano 2 tenían también cerámica del Temprano I, en el caso del Temprano 3 estos sólo 


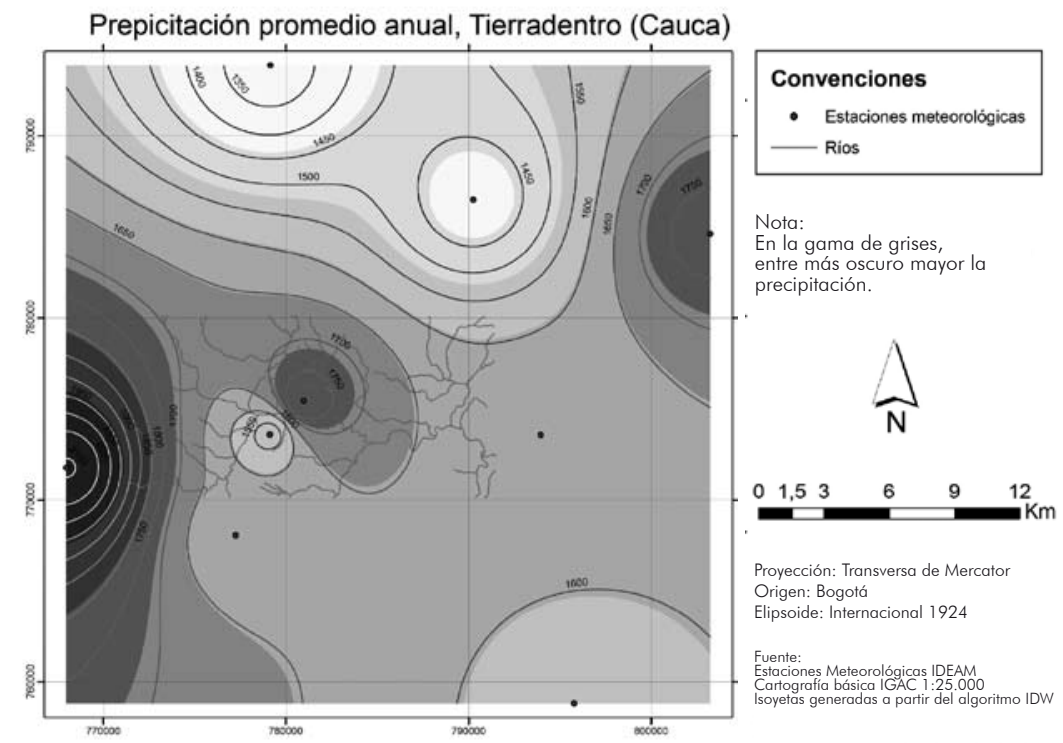

LA FIGURA INDICA LA MAYOR PLUVIOSIDAD HACIA LAS REGIONES MÁS ALTAS Y LA CUENCA DE LA QUEBRADA DE SAN ANDRÉS EN RELACIÓN CON OTRAS SUBREGIONES. MAPA ELABORADO POR ANDRÉS GUHL.

alcanzan el 4.I8\%, aunque el número de pruebas aumento en cerca de $477 \%$, lo que sugiere una variación en la estructura económica de las residencias de Tierradentro durante este período. Este tipo de ruptura sugiere que la variación en la distribución de la población no tuvo como incentivo la productividad de los suelos y se puede especular que tuvo que ver con aspectos religiosos, ideológicos o políticos, ya que estos cambios coinciden con la aparición de la estatuaria y los montículos.

TABLA 8

\begin{tabular}{|l|c|r|r|r|r|r|}
\hline \multicolumn{1}{|c|}{ Tipo } & Período & $\begin{array}{c}\text { Área ocupada } \\
\text { período } \\
\text { anterior, ha. }\end{array}$ & $\begin{array}{c}\text { Área } \\
\text { ha. } \\
\text { Total }\end{array}$ & $\begin{array}{c}\text { \%o } \\
\text { Ocupada } \\
\text { período } \\
\text { anterior }\end{array}$ & $\begin{array}{c}\text { Área } \\
\text { ocupada }\end{array}$ & $\begin{array}{c}\text { Tasa de } \\
\text { Creci- } \\
\text { miento }\end{array}$ \\
\hline Tachuelo & $\mathrm{T} 1$ & & & & 19.39 & \\
\hline Planaditas & $\mathrm{T} 2$ & 3.06 & 31.3 & $9.77 \%$ & 31.3 & $61.4 \%$ \\
\hline Lourdes & $\mathrm{T} 3$ & 7.56 & 180.7 & $4.18 \%$ & 180.7 & $477.3 \%$ \\
\hline Medio & $\mathrm{M}$ & 118.69 & 484 & $24.52 \%$ & 484 & $167.8 \%$ \\
\hline Tardío & $\mathrm{T}$ & 230.68 & 751.4 & $30.70 \%$ & 751.4 & $55.2 \%$ \\
\hline Moderno & $\mathrm{M}$ & 24.17 & 76.22 & $31.71 \%$ & 76.22 & $-89.9 \%$ \\
\hline
\end{tabular}

PeRSistencia DE LA OCUPACIÓN 
Lo cierto es que aunque la distribución general de los asentamientos no se puede explicar siempre a partir de condiciones agrícolas, la de los conjuntos más grandes de estatuaria se ubica sobre áreas de suelos adecuados para la agricultura. Pero igual se puede afirmar que existen estatuas en lugares que no son los mejores para sembrar. Por otra parte, un estudio de A. Dever (I999) sobre la distribución de las concentraciones de estatuas en San Andrés y en El Hato descarta otras posibilidades, por ejemplo que los grandes conjuntos de estatuas de esos lugares puedan ser explicados a partir de la visibilidad de los lugares donde se encuentran. Las estatuas de la parte alta de la región son poco visibles desde otros sitios.

Independiente de las condiciones de los suelos, la altura sobre el nivel del mar pudo haber sido una variable significativa del poblamiento. Y en efecto la distribución por alturas sobre el nivel del mar ofrece algunos contrastes interesantes entre períodos (tabla 9). En el período Temprano I el intervalo entre los I.300 y I.400 concentra la mayor parte de la cerámica (40.4\%), mientras en Temprano 2 el rango de altura más rico en evidencias de cerámica corresponde a los I.500-I.600, pero en un porcentaje menor (29.5\%). En ambos casos, el mayor poblamiento está por debajo de los I.60o metros: en el Temprano I, el 6r\% del área, y en el Temprano 3, el 55\%. En ese sentido el contraste con el período Temprano 3 es importante puesto que durante este, la mayor parte de las evidencias se ubican entre los 1.900 y $2.000 \mathrm{msnm}$ (30.3\%); el porcentaje por debajo de los I.60o msnm se reduce a $29 \%$, mientras el grueso del área se encuentra entre los I.600 y $2.000 \mathrm{msnm}$. En el Período Medio y Tardío continúa la misma tendencia que las alturas entre los I.600 y $2.000 \mathrm{msnm}$ sean las más habitadas. Durante la ocupación Moderna la habitación tiende a repartirse de forma más homogénea con relación a la altura sobre el nivel del mar. Resultados muy similares se obtienen si el análisis se repite usando rangos de altura de $400 \mathrm{~m}$ (tabla Io). Los anteriores cambios sólo parcialmente pueden tener sentido en términos climáticos. Antes del inicio de la era a.D., se reporta en el Valle de la Plata un clima más húmedo y frío que el actual, razón por la cual las tierras más altas pudieron parecer más atractivas para la agricultura y la ocupación humana (Drennan, R., et. al, 2006, p. 40). Lo anterior podría dar cuenta del aumento de población por encima de los I.60o msnm a partir del Período Temprano 3; sin embargo, no ayuda a explicar que la mayor 
ocupación de las alturas por encima de los 2.00o corresponde al Período Temprano 2.

TABLA 9

\begin{tabular}{|l|r|r|r|r|r|r|}
\hline & Temprano 1 & Temprano 2 & \multicolumn{1}{c|}{ Temprano 3 } & \multicolumn{1}{c|}{ Medio } & \multicolumn{1}{c|}{ Tardío } & \multicolumn{1}{c|}{ Moderno } \\
\hline$>2500$ & & & & & $0.03 \%$ & \\
\hline $2400-2500$ & $1.92 \%$ & & & $0.20 \%$ & $0.28 \%$ & \\
\hline $2300-2400$ & & & $0.31 \%$ & $0.24 \%$ & $0.23 \%$ & $1.63 \%$ \\
\hline $2200-2300$ & & $0.78 \%$ & $1.77 \%$ & $0.18 \%$ & $0.52 \%$ & $0.33 \%$ \\
\hline $2100-2200$ & $5.77 \%$ & $10.85 \%$ & $3.78 \%$ & $3.23 \%$ & $4.04 \%$ & $2.61 \%$ \\
\hline $2000-2100$ & $5.77 \%$ & $6.20 \%$ & $8.78 \%$ & $5.37 \%$ & $5.57 \%$ & $\mathbf{1 8 . 2 4} \%$ \\
\hline $1900-2000$ & $1.92 \%$ & $6.2 \%$ & $\mathbf{3 0 . 2 8} \%$ & $\mathbf{1 2 . 3 6} \%$ & $\mathbf{1 3 . 3 3} \%$ & $11.07 \%$ \\
\hline $1800-1900$ & & $1.55 \%$ & $\mathbf{1 2 . 1 0} \%$ & $\mathbf{1 5 . 8 9} \%$ & $\mathbf{1 3 . 0 3} \%$ & $3.26 \%$ \\
\hline $1700-1800$ & $5.77 \%$ & $.78 \%$ & $7.94 \%$ & $\mathbf{1 1 . 8 5} \%$ & $\mathbf{1 4 . 2 1 \%}$ & $10.75 \%$ \\
\hline $1600-1700$ & $\mathbf{1 7 . 3 1} \%$ & $\mathbf{1 3 . 1 8} \%$ & $6.32 \%$ & $\mathbf{1 3 . 0 4} \%$ & $\mathbf{9 . 4 2} \%$ & $14.33 \%$ \\
\hline $1500-1600$ & $19.23 \%$ & $29.46 \%$ & $9.24 \%$ & $8.20 \% \%$ & $\mathbf{1 1 . 1 4 \%}$ & $6.84 \%$ \\
\hline $1400-1500$ & $1.92 \%$ & $\mathbf{2 2 . 4 8} \%$ & $7.70 \%$ & $9.73 \%$ & $\mathbf{1 1 . 4 1 \%}$ & $8.79 \%$ \\
\hline $1300-1400$ & $\mathbf{4 0 . 3 8} \%$ & $3.88 \%$ & $\mathbf{1 0 . 7 9} \%$ & $\mathbf{1 8 . 0 5} \%$ & $\mathbf{1 3 . 2 2} \%$ & $\mathbf{2 2 . 1 5 \%}$ \\
\hline $1200-1400$ & & & $1.00 \%$ & $1.66 \%$ & $3.57 \%$ & \\
\hline
\end{tabular}

DisTRIBUCIÓN DEL ÁREA DE OCUPACIÓN POR RANGOS DE ALTURA EN TIERRADENTRO, INTERVALOS DE 100 M. SE RESALTAN PORCENTAJES ELEVADOS

TABLA IO

\begin{tabular}{|l|r|r|r|r|r|r|}
\hline & Temprano 1 & Temprano 2 & Temprano 3 & Medio & Tardío & Moderno \\
\hline$>2000$ & $14 \%$ & $24 \%$ & $15 \%$ & $10 \%$ & $12 \%$ & $24 \%$ \\
\hline $1600-2000$ & $25 \%$ & $21 \%$ & $56 \%$ & $53 \%$ & $49 \%$ & $39 \%$ \\
\hline $1200-1600$ & $61 \%$ & $55 \%$ & $29 \%$ & $37 \%$ & $39 \%$ & $37 \%$ \\
\hline
\end{tabular}

DiSTRIBUCIÓN DEL ÁREA DE OCUPACIÓN POR RANGOS DE ALTURA EN TIERRADENTRO, INTERVALOS DE $400 \mathrm{M}$

Un resultado que complementa el anterior análisis se refiere a la comparación de la altura en que se encuentran los sitios por período en términos de una medida central (promedio) y dispersión (gráfico 4). El estudio estadístico basado en el promedio de altura de los sitios por divisiones cronológicas muestra que el poblamiento más temprano tiende a darse en las tierras más bajas, con una preferencia en cada uno de los períodos siguientes a aumentar la ocupación de regiones más elevadas. A partir del Período Medio la situación se estabiliza con un leve descenso en el promedio de altura con respecto al Período Temprano 3. 
GRÁFICO 4

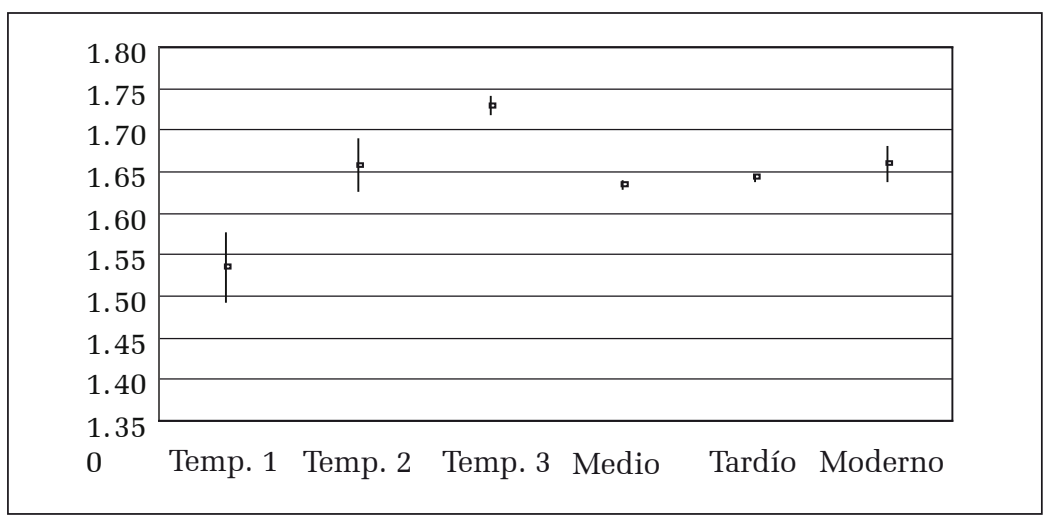

Promedio de Altura MSNM de LA CERÁmicA DE CADA PERíodo (80\% PROBABILIDAD)

\section{Conclusiones}

AS INVESTIGACIONES ARQUEOLÓGICAS ADELANTADAS POR EL PAT HAN reconstruido, en líneas generales, el poblamiento humano en -Tierradentro. La secuencia tiene claros vínculos con la que se ha estudiado en el Alto Magdalena, región de la que hace parte tanto en términos geográficos como culturales. No obstante, se sugieren algunas diferencias en la cronología: una duración un poco mayor de los períodos Temprano 3 y Medio, entre las más importantes. La cerámica más característica de cada una de las ocupaciones se encuentra también en el Alto Magdalena, si bien desde el inicio hasta el final, en especial en los períodos Temprano y Tardío, parecen reconocerse variantes regionales de alfarería del área de estudio.

La ocupación humana, al principio poco densa, se inició quizá desde el 1000 a. C., prefiriendo vivir sobre suelos más apropiados para la agricultura. Desde un comienzo, aunque la población era escasa, se pueden encontrar contrastes regionales en la forma como se ocupó el espacio, que tienden a disminuir en la parte más tardía de la secuencia. Comparado como un todo, y a lo largo toda de la secuencia, Tierradentro parece haber tenido una densidad demográfica más alta que la de la parte baja del río de La Plata, pero menor que la de la parte más alta de la cuenca del mismo río. Según los cálculos realizados, la población aumentó de 
manera significativa en dos ocupaciones: el Temprano 3, es decir hacia el 300 a. C., y el Tardío, después del I300 d. C. La población del Período Medio, según algunos de los estimativos, aumentó en una proporción menor que en otros períodos o incluso pudo haber disminuido un poco si se aceptan algunos de los indicadores utilizados para calcular índices relativos de población. Por otra parte, sin importar qué indicador se escoja, después de la llegada de los españoles el número de habitantes descendió de forma considerable. Dimensionar en términos absolutos la secuencia de cambio demográfico ocurrido después de la Conquista es difícil, pero para dar una impresión, muy general, del declive demográfico ocurrido basta recordar que la densidad de población hoy en día de Tierradentro parece inferior a la del Período Tardío y tal vez comparable a la del Período Medio.

En términos de cambios sociales, los más significativos en Tierradentro también siguieron líneas semejantes a las encontradas en el Alto Magdalena. Durante el Período Temprano 3, se amplió la distribución de la población, se inició la concentración de población en lugares donde se desarrollaría la construcción de montículos y estatuaria y quizá se comenzó la elaboración de objetos orfebres. La información sobre estos procesos es todavía insuficiente como para precisar mejor las características de la organización social indígena durante el Período Temprano 3. No se han llevado a cabo aún excavaciones de comunidades o unidades domésticas que permitan conocer mejor la naturaleza de la diferenciación social durante este período. En todo caso, es claro que la ocupación Temprano 3 es fundamental para entender la secuencia de cambio social en Tierradentro y que futuras investigaciones relacionadas con él son necesarias.

Por lo pronto, se puede afirmar que el Período Temprano 3 coincide con los más trascendentales cambios en la forma como la población se distribuyó en el espacio. Por ejemplo, si bien la cuenca de la Quebrada de San Andrés siempre concentró mayor cantidad de gente en relación con su tamaño, esa tendencia es más notoria en el Temprano 3 (y en menor grado en el Medio), lo cual es interesante dada la concentración de hipogeos y la notable cantidad de estatuaria que se encuentra en esa subregión. También se debe anotar que el Período 3 coincidió con un cambio en la forma como la población se distribuyó en términos de altura sobre el nivel del mar, esta prefirió ocupar elevaciones entre los I.600 y 2.000 msnm 
cuando la tendencia en ocupaciones anteriores fue a instalarse en tierras por debajo de los $1.600 \mathrm{msnm}$.

El Período Medio en Tierradentro corresponde a una ocupación que se repartió de forma más homogénea y se desarrollaron concentraciones de población conocidas por sus montículos y/o estatuaria, en especial en la cuenca de la Quebrada de San Andrés y en El Hato. En líneas generales algunas de las características del Período Medio continúan tendencias de la ocupación previa, aunque se debe resaltar que, como se anotó más arriba, el ritmo de crecimiento demográfico disminuyó. Si se utilizan los análisis de distribución de gente teniendo en cuenta tres categorías de suelos, se observa un incremento importante en el porcentaje de personas que ocupaban los terrenos de peores condiciones agrícolas. Esto sugiere que la escasez de tierras fértiles se debe descartar como razón para el desarrollo del liderazgo político que evidencian los montículos y la estatuaria, al menos a nivel regional.

Durante el Período Medio hay evidencias de orfebrería, a pesar de que parece escasa al menos en relación con la que se desarrolló en la misma época en otras regiones del suroccidente de Colombia. Se sabe muy poco sobre los ajuares funerarios de este período, aunque al menos en El Hato parece haberse formado un importante núcleo de población similar en muchos aspectos a los que existían en el Alto Magdalena, que incluyen los característicos montículos con entierros y estatuaria. Sobre los individuos enterrados en El Hato poco se sabe, aunque al igual que en el caso del Alto Magdalena se puede especular que se trataba de personas especiales, cuya memoria se quería preservar después de muertos. Sin embargo, se debe ser cauto a la hora de interpretar el carácter específico de la complejidad social que implica la existencia de orfebrería y estatuaria. Los cálculos de R. Drennan sobre la movilización de trabajo para producir la estatuaria y montículos en San Agustín concluyen que no se trataba de obras públicas a gran escala (Drennan, R., 2000, p. 19) y lo mismo resulta cierto en Tierradentro, donde incluso los montículos que se encuentran en El Hato son más pequeños que los que sirvieron a R. Drennan para hacer sus cálculos (Mesita A). Dado que los contextos en los que se ha encontrado la orfebrería son desconocidos, es difícil inferir cuestiones relacionadas con jerarquización social: lo cierto es que la sola presencia de objetos de metal no sirve para inferir marcadas diferencias sociales (Langebaek, C. H. , 2003). Por ahora las mejores 
esperanzas de conocer en detalle la naturaleza de la jerarquización social del Período Medio descansan en los estudios de unidades domésticas que efectuó el PAT en el asentamiento de Inzá y que aún se encuentran en proceso de análisis.

La información disponible sobre la ocupación Tardía en Tierradentro sugiere que la historia prehispánica culminó como resultado de un proceso continuo. No hay evidencias arqueológicas que respalden la idea de que los últimos habitantes prehispánicos de Tierradentro fueran recién llegados. Aunque la escala cronológica es lo suficientemente gruesa como para que se pudiera especular sobre el arribo de los nasa en algún momento antes de la Conquista europea, la realidad es que los materiales arqueológicos encontrados indicarían que aún si ese fue el caso su alfarería habría sido muy similar a la que usaban los ocupantes previos. La región de Tierradentro tiene evidencias de la ocupación continua y prolongada de algunos sitios importantes desde el Temprano hasta más allá del siglo XVI. Después de la Conquista desaparecen las concentraciones de población propias de los últimos períodos prehispánicos, pero aún así buena parte de la ocupación humana permanece en sitios que también fueron habitados en el Período Tardío. Tampoco parece fácil sostener la idea de que el último período prehispánico marca una decadencia en relación con el Período Medio. En términos demográficos la población del período Tardío aumentó en relación con la de este último y se dio la consolidación de sitios de cierto tamaño. La ocupación tardía se caracteriza también por una orientación hacia los suelos más fértiles (si se utiliza el criterio de la división de suelos en tres categorías). La información aportada por el estudio del asentamiento de Inzá sugiere que en este período existían unidades domésticas más grandes que otras y que las primeras usaban una cerámica singular, mejor elaborada y más grande, que no se conseguía en las más pequeñas. No obstante, no disponemos aún de estudios más concluyentes sobre la naturaleza de la diferenciación social en este período. De lo que sí hay buenos indicios es de que la ocupación Tardía se prolongó hasta bastante después de la Conquista, aunque la población descendió de forma abrupta, a niveles que sugieren que incluso hoy permanece por debajo de lo alcanzado siglos antes de la llegada de los españoles. 


\section{BiBLIOGRAFÍA}

Aparicio, J. R. (I999). Proceso de cambio social entre el Período Medio y el Tardío en la aldea prehispánica de Inzá, Cauca. Informe de trabajo de campo, Universidad de los Andes-PAT.

Astudillo, D. A. (2008). Cambio o resistencia en asentamientos de los resguardos de Tumbichucue y Calderas. Una aproximación etnoarqueológica en Tierradentro. Trabajo de grado, Departamento de Antropología, Universidad del Cauca.

BLICK, J. (1996). Recent Archaeological Investigations in Tierradentro, Colombia: Stratigraphic Excavations and Regional Survey-Report of Investigations (I994-I995 Season). Ponencia en la 6I reunión de la Society for American Archaeology. Nueva Orleans.

Cardale de SchrimpfF, M., Bray, W., Gähwiler-Walder, T. y Herrera, L. (I992). Calima-Diez mil años de historia en el suroccidente de Colombia. Bogotá: Editorial Printer Colombiana.

Cuéllar, A. (I995). Función y distribución de la estatuaria en Tierradentro. Informe de campo, Departamento de Antropología, Universidad de los Andes.

(1997). Comparación de dos plataformas arqueológicas en un sitio de habitación prehispánica en Inzá-Cauca. Tesis de grado, antropología, Universidad de los Andes, Bogotá.

Chaves, A. y Puerta M. (1980). Entierros primarios de Tierradentro. Bogotá: Fundación de Investigaciones Arqueológicas Nacionales, FIAN.

(1985). Tierradentro. Bogotá: El Áncora Editores.

(I986). Monumentos Arqueológicos de Tierradentro. Bogotá: Biblioteca Banco Popular.

(I990a). Tierradentro. En M. Jimeno (Ed). Parques Arqueológicos (87-II4). Bogotá: Instituto Colombiano de Cultura.

(I99ob). Una nueva fecha para la cultura de Tierradentro. Universitas Humanistica, 33: 3I-38.

Dever, A. (I999). El paisaje arqueológico en Tierradentro: una aproximación al análisis de la visibilidad de poblaciones prehistóricas. Arqueología del Área Intermedia, I: 9-48.

Drennan, R. (Ed). (I985). Regional Archaeology in the Valle de la Plata, Colombia. Technical Reports No. I6. Ann Arbor: University of Michigan Museum of Anthropology.

Drennan, R. (1993). Part One: Ceramic Classification, Stratigraphy, and Chronology. En R. Drennan, M. Taft y C. Uribe (Eds). Prehispanic 
Chiefdoms in the Valle de la Plata, Vol. 2 (3-IO4). Memoirs Latin American Archaeology 5. Pittsburgh: University of Pittsburgh.

(I995). Mortuary Practices in the Alto Magdalena: The Social Context of the "San Agustin Culture". En T. Dillehay (Ed). Tombs for the Living: Andean Mortuary Practices (79-110). Washington: Dumbarton Oaks Research Library and Collection.

(I996). One for All and All for One: Accounting for variability without Losing Sight of Regularities in the Development of Complex Society. En Jeanne Arnold (Ed.) Emergent Complexity: The Evolution of Intermediate Societies (25-34). Ann Arbor: International Monographs in Prehistory.

(2000). Las sociedades prehispánicas del Alto Magdalena. Bogotá: Instituto Colombiano de Antropología e Historia, ICANH.

(2008). Chiefdoms of Southwestern Colombia. En Silverman H. y W. Isbell (Eds.) Handbook of South American Archaeology (38I-403). New York: Springer.

Drennan, R. y QuATtrin, D. W. (I996). Patrones de asentamiento y organización sociopolítica en el valle de La Plata. En Gnecco, C. (Ed.) Perspectivas regionales en la Arqueología del suroccidente de Colombia y norte del Ecuador (85-I08). Popayán: Universidad del Cauca.

Drennan, R. M., M. Taft, y C. A. Uribe (Eds.). (I993). Prehispanic Chiefdoms in the Valle de la Plata. Volume 2: Ceramics-Chronology and Craft Production. University of Pittsburgh Memoirs in Latin American Archaeology No. 5. Pittsburgh and Santafé de Bogotá: University of Pittsburgh-Universidad de Los Andes.

Drennan, R., Jaramillo, L. G., Ramos, E., SÁnchez, C. A., Ramírez, M. Á. y URIBE, C. A. (I99I). Regional Dynamics of Chiefdoms in the Valle de la Plata, Colombia. Journal of Field Archaeology. I8: 297-317.

Drennan, R. y Boada, A. M. (2006). Patrones Demográficos. En Cacicazgos Prehispánicos del Valle de La Plata, Tomo 5 (59-82). University of Pittsburgh Memoirs in Latin American Archaeology, 16. Pittsburgh and Bogotá: University of Pittsburgh-Universidad de los Andes.

Drennan, R., Jaramillo, L. G; SÁnchez, C. A.; Ramírez, M. Á y Ramos, E. (2006). General Environmental Characteristics and Settlement Distribution. En R. Drennan, M. Taft y C. Uribe (Eds). Prehispanic Chiefdoms in the Valle de la Plata, Vol. 5 (29-59). Memoirs Latin American Archaeology 5. Pittsburgh: University of Pittsburgh.

Drennan, R., Peterson, Ch. E., Indrisano, G. G., Mingyu, T., Shelach, G., YAnging, Z., Liduff, K. M. y ZhizHONG, G. (2003). Approaches to Region al Demographic Reconstruction. En The Chifeng International Collaborative Archaeological Research Project (Ed.) Regional Archaeology 
in Eastern Inner Mongolia: A Methodological Exploration (152-65). The Chifeng International Collaborative Archaeological Research Project. Beijing: Science Press.

Duque, L. (1963). San Agustín-Reseña Arqueológica. Bogotá: Editolaser. (1979). La pieza del Museo. Boletín Museo Oro, año 2: s.p.

Earle, T. (1996). How Chiefs come to Power. The Political Economy in Prehistory. Stanford: Stanford University Press.

Feinman, G. y Neitzel, J. (1984). Too Many Types: An Overview of Prestate Societies in the Americas. En M.B. Schiffer (Ed). Advances in Archaeological Method and Theory, 7 (39-IO2). Orlando: Academic Press.

FindJI, M. T. y RojAs, J. M. (1985). Territorio, economía y sociedad Páez. Cali: CIDSE, Universidad del Valle.

FRIEDE, J. (I967). Los Andaquí 1538-1947. Historia de la aculturación de una tribu selvática. México: Fondo de Cultura Económica, FCE.

GÄHWILER-WALDER, T. (I988). Archaeological Investigations in the Pavas-La Cumbre Región. ProCalima, 5: 50-60.

George, N. (I998). Excavación de una plataforma de vivienda en Tierradentro-Plataforma Inzá 25. Trabajo de grado, Departamento de Antropología, Universidad de los Andes.

GIRALDO, S. (1995). El modelo de umbral explotable de recursos cerámicos: el caso de Tierradentro. Informe de de campo, Departamento de Antropología, Universidad de los Andes.

(1997). Comparación de dos plataformas arqueológicas en un sitio de habitación prehispánica en Inzá, Cauca. Trabajo de grado, Departamento de Antropología, Universidad de los Andes, Bogotá.

Gnecco, C. y MarTínez, J. R. (I992). Dos Alcarrazas Ilama en Tierradentro. Boletín Museo del Oro, 32 (3): 178-18I.

Gnecco, C. y Hernández, C. (2008). History and Its Discontents-Stone Statues, Native Histories, and Archaeologists. Current Anthropology, 49 (3): 439-466.

GRoот, A. M. (1974). Excavación arqueológica en Tierradentro. Estudio sobre cerámica y su posible uso en la elaboración de la sal. Trabajo de grado, Departamento de Antropología, Universidad de los Andes, Bogotá.

GuHL, A. (1996). Aplicación de un SIG al manejo integral de una cuenca: Quebrada de San Andrés, Tierradentro. Trabajo de grado, Departamento de Ingeniería Civil, Universidad de los Andes.

HERnÁNDEZ DE Alba, G. (I938). Investigaciones arqueológicas en Tierradentro. Revista de Las Indias, 2 (9): 29-35 у 2 (IO): 9I-IOI. 
Humar, Z. (I998). Excavación arqueológica en la plataforma Inzá 22. Trabajo de grado, Departamento de Antropología, Universidad de los Andes, Bogotá.

Jaramillo, L. G. (I996). Cacicazgos prehispánicos en el Valle de la Plata 3. La Estructura Socioeconómica de las Comunidades del Formativo 3. Memoirs in Latin American Archaeology, Io. Pittsburgh: University of Pittsburgh.

JiméNEz, B. (I995). Estudios de Suelos para el Proyecto Arqueológico de Tierradentro (inédito).

Kaufman, T. (I990). Language Classification in South America: What We Know and How to Know More. En D. L. Payne (Ed.) Amazonian Linguistics: Studies in Lowland South American Languajes (I3-74). Austin: University of Texas Press.

LANGEBAeK, C. H. (I995a). Informe preliminar sobre actividades del Proyecto Tierradentro. Revista de Antropología y Arqueología, 8 (I-2): 226-236.

(I995b). Informe final de investigaciones en Tierradentro. Instituto Colombiano de Antropología e Historia (inédito). (1998). Arqueología de Tierradentro: Procesos de cambio social del Iooo a. C al presente en una región de Colombia (inédito).

(2003). The Political Economy of Pre-Columbian Gold Work: Four Examples from Northern South America. En Quilter J. y. Hoopes, J. W. (Eds.) Gold and Power in Ancient America (245-78). Washington: Dumbarton Oaks Library and Collections.

(2004). Secuencias y procesos. Estudio comparativo del desarrollo de jerarquías de asentamiento prehispánicas en el norte de Suramérica. Revista del Área Intermedia, 6: 199-248.

Langebaek, C. H. y Dever, A. (2000). Arqueología del Bajo Magdalena: un estudio de los primeros agricultores del Caribe colombiano. Bogotá: Instituto Colombiano de Antropología e Historia, ICANH.

Londoño, J. (I955). La geografía y el hombre en Tierradentro. Revista Colombiana de Antropología, 4: III-II9.

Long, S. y Yanguez, J. (I97I). Excavaciones en Tierradentro. Revista Colombiana de Antropología, I5: 9-I28.

Llanos, H. (1993). Presencia de la cultura de San Agustín en la depresión cálida del valle del río Magdalena. Bogotá: Fundación de Investigaciones Arqueológicas Nacionales, FIAN, Banco de la República.

PÉREZ DE BARRADAs, J. (I937a). Arqueología y antropología precolombinas de Tierradentro. Bogotá: Ministerio de Educación Nacional. 
Arqueología regional en Tierradentro, Cauca, Colombia

PÉrez de BARradas, J. (I937b). La máscara de Inzá. Revista de Indias, I (5): $3-7$.

Preuss, K. T. (I974). Arte Monumental Prehistórico-Excavaciones hechas en el Alto Magdalena y San Agustín (Colombia). Comparación arqueológica con las manifestaciones artísticas de las demás civilizaciones americanas. Bogotá: Universidad Nacional de Colombia.

PuERTA, M. (I973). Excavaciones arqueológicas en la región de Tierradentro. Trabajo de grado, Departamento de Antropología, Universidad de los Andes.

\section{Carrera $7^{\mathrm{a}}$.}

(2005). Tierradentro-La Tierra del Duende. Bogotá: Editorial

RAPPAPORT, J. (I982). Tierra Páez: la etnohistoria de la defensa territorial entre los paeces de Tierradentro. Informe a la Fundación de Investigaciones Arqueológicas Nacionales, FIAN (inédito).

Reichel-Dolmatoff, G. (I97I). San Agustín. A Culture of Colombia. New York: Praeger Publishers.

Rubiano, J. C. (I999). Vivienda y cacicazgos: el caso de Tierradentro. Trabajo de grado, Departamento de Antropología, Universidad de los Andes, Bogotá.

SAnabria, O. L. (200I). Manejo vegetal en agrosistemas tradicionales de Tierradentro, Cauca, Colombia. Popayán: Editorial Universidad del Cauca.

SÁnchez, C. (2005). Sociedad y agricultura Prehispánica en el Alto Magdalena. Informes del Instituto Colombiano de Antropología e Historia, 4. Bogotá: Instituto Colombiano de Antropología e Historia, ICANH.

SÁnchez, C. (2000). Análisis arqueológicos de los posibles recursos alimenticios en grupos humanos precolombianos de la Cultura Tierradentro. Informe de campo, Departamento de Antropología, Universidad de los Andes.

SEVILla CaSas, E. (1976). Estudios antropológicos sobre Tierradentro. Informe de Investigación. Cali: Fundación para Educación Superior, FES.

(I943). La arqueología de Tierradentro. Revista del Instituto Etnológico Nacional, I (entrega I): II7-30.

Sotomayor, M. L. y Uribe, M. V. (I987). Estatuaria del Macizo Colombiano. Bogotá: Instituto Colombiano de Antropología, ICAN.

Trimborn, H. (I949). Señorío y barbarie en el Valle del Cauca. Estudio sobre la antigua civilización quimbaya y grupos afines del oeste de Colombia. Madrid: Consejo Superior de Investigaciones CientíficasInstituto Gonzalo Fernández de Oviedo. 
URiBE, M. A. (I986). De los nombres de las gentes y de los ríos y de las montañas y de otros elementos del paisaje: un estudio etnohistórico de la antroponomia y la toponimia del Alto Magdalena. Trabajo de grado, Departamento de Antropología, Universidad de los Andes.

White, E. (I934). Informe presentado por el ingeniero de minas Henrique E. White Uribe, sobre los estudios verificados en los Municipios del Inzá y Páez (Tierradentro), en el Departamento del Cauca. Boletín de Minas y Petróleo, I2 (67-72): 24I-258.

Yanguez, J. (Ig68). Arqueología de Tierradentro, Departamento del Cauca, República de Colombia, Sur América. Trabajo de grado, Departamento de Antropología, Universidad de los Andes.

Yunis, J., Yunis, E. J y Yunis, E. (200I). Genetic Relationship of the Guambiano, Páez, and Ingano Amerindians of Southwestern Colombia Using Major Histocompatibility Complex Class II Haplotypes and Blood Groups. Human Inmunology, 62: 970-978.

ZARUR, F. (I998). Arqueología de Tierradentro-Cronología y cortes estratigráficos en los montículos de El Hato. Trabajo de grado, Departamento de Antropología, Universidad de los Andes. 